\title{
Teoria da Resposta ao Item (TRI) Modelos Multidimensionais
}

\author{
RONALD TARGINO NOJOSA \\ Professor substituto do Departamento de Estatística e Matemática Aplicada da \\ Universidade Federal do Ceará; colaborador no Laboratório de Estatística e \\ Medidas Educacionais (LEME) da Universidade Federal do Ceará. \\ Mestre em Estatística Aplicada, sub-área Avaliaçăo Educacional \\ rtarginon@bol.com.br
}

\begin{abstract}
Resumo
Os modelos de respostas ao item utilizados, atualmente, limitam-se a avaliaçoes que medem um traço latente (habilidade) que pode ser representado por uma única dimensăo (avaliaçōes unidimensionais). Algumas avaliaçōes, seja pela construçŭo dos ittens ou pela própria finalidade da aplicação, não podem, a principio, ser consideradas unidimensionais. Este é o caso do Exame Nacional do Ensino Médio - ENEM, que fol estruturado segundo uma matriz de 5 competéncias. Este trabalho apresenta, primeiramente, conceitos básicos da TRI $\mathrm{e}$ introduz técnicas destinadas à determinaçâo da dimensionalidade de um conjunto de dados. A Análise Fatorial de Informaçăo Plena está entre essas técnicas e é proposta como ferramenta para a verificação da dimensionalidade das provas do ENEM. Os resultados desse estudo mostraram que a habilidade medida pelo ENEM do ano de 1999 pode ser representada por pelo menos 5 dimensỏes. $O$ trabalho apresenta, ainda, modelos que tornam possível a modelagem de dados em avaliaçōes multidimensionais.

Palavras-chave: Teoria da Resposta ao Item Multidimensional, Dimensionalidade, Análise Fatorial, Teoria da Resposta ao Item.
\end{abstract}

\section{Resumen}

Actualmente, los modelos de respuesta al ftem utilizados se limitan a evaluaciones que miden un trazo latente (habilidad) que puede ser representado por una única dimensión, evaluaciones unidimensionales. Algunas evaluaciones, sea por la construccion de cada item, sea por la propia finalidad de la aplicación, no pueden en primer instancia, ser consideradas unidimensionales. Es el caso del Exame Nacional do Ensino Médio - ENEM, estructurado según una matriz de cinco competencias. En primer plano, son presentados en este trabajo conceptos básicos de la TRI y se introducen técnicas destinadas a determinar la dimensionalidad de una base de datos. Para verificar tal dimensionalidad en las pruebas del ENEM, se propone, de entre varias técnicas, la Análisis Factorial de Información Plena. Una de sus grandes ventajas es la de permitir testar la significáncia del aumento en la dimensión de un conjunto de datos. Los resultados de este estudio ostentan que la habilidad medida por el ENEM en el affo de 1999 puede ser representada al menos por cinco dimensiones. Incluso en evaluaciones de tipo unidimensionales, esta análisis es muy importante dada la dificultad en la elaboración de cada item que conserven la unidimensionalidad. Además, para evaluaciones multidimensionales, el trabajo también expone modelos que posibiliten amoldar sus datos.

Palabras-clave: Teoria de la Respuesta al ftem Multidimensional, Dimensionalidad, Análisis Factorial, Teoría de la Respuesta al ftem. 


\begin{abstract}
The item response models currently applied in most educacional evaluations seek to measure a latent trait (ability) which can be represented by only one dimension (unidimensionality). Some educacional evaluations, however, do not fit into a onedimensional framework. This is case of the 'Exame Nacional do Ensino Médto' (ENEM), which has been designed according to a matrix of five different skills. At the outset, this article presents a brief overview of the unidimensional Item Response Theory and some tecniques that are helpful in determining the dimensionality of a given set of items. One of these techniques is the Full Information Factorial Analysis, which we propose as a way to check the dimensionality of ENEM. The results suggest that this exam in 1999 is at least fivefold dimensional. We also present models designed to model multidimensional evaluations.

Keywords: Item Response Theory, Multidimensional Item Response Theory, Dimensionality, Factor Analysis.
\end{abstract}




\section{Introdução}

Os modelos de resposta ao item atualmente utilizados limitam-se a avaliaçōes que medem um traço latente (habilidade) que pode ser representado por uma única dimensão (avaliações unidimensionais). Algumas avaliações, seja pela construção dos itens ou pela própria finalidade da aplicaçăo, não podem, em princípio, ser consideradas unidimensionais. Este é o caso do Exame Nacional do Ensino Médio (ENEM), que foi estruturado segundo uma matriz de 5 competencias.

Este trabalho aborda, inicialmente, conceitos importantes da Teoria da Resposta ao Item (TRI) unidimensional. Em seguida, são apresentadas técnicas destinadas à determinação da dimensionalidade de um conjunto de dados e modelos que tornam possível a modelagem para avaliações multidimensionais. A parte final do trabalho apresenta uma aplicação aos dados do ENEM do ano de 1999.

\subsection{Modelos Unidimensionais}

Modelos unidimensionais da Teoria da Resposta ao Item vêm sendo aplicados nos últimos anos em importantes avaliaçōes educacionais. Esses modelos têm como suposição fundamental a unidimensionalidade do teste, ou seja, a suposição de que o teste está medindo uma única habilidade (traço latente). As principais diferenças entre os modelos está na forma matemática da Curva Característica do Item e no número de parametros do modelo. Esses modelos são expressões matemáticas que fornecem a probabilidade de resposta correta a um item como função da habilidade do individuo e dos parametros dos itens.

Dentre os modelos unidimensionais propostos na literatura, um dos mais utilizados é o modelo logístico de 3 parâmetros proposto por Birbaum (1957). Esse modelo é empregado em itens de múltipla escolla do tipo certo/errado e é dado por

$$
P\left(X_{i j}=1 \mid \theta_{j}\right)=c_{i}+\left(1-c_{i}\right) \frac{1}{1+e^{-D a_{i}\left(\theta_{j}-b_{j}\right)}}
$$


onde

$X_{i j}$ é uma variável dicotômica que assume os valores 1 , quando o $j$-ésimo individuo responde corretamente ao item $i$, ou 0 quando o $j$-ésimo indivíduo não responde corretamente ao item $i$, com $i=1,2, \ldots, p$ e $j=1$, $2, \ldots, N$;

$P\left(X_{i j}=1 \mid \theta_{j}\right)$ é a probabilidade de um indivíduo $j$ com habilidade $\theta_{\mathrm{j}}$ responder corretamente ao item $i$;

$\theta_{j}$ representa a habilidade (traço latente, traço ou proficiência) do $j$ ésimo indivíduo;

$a_{i}$ é o parâmetro de discriminação do item $i$;

$b_{i}$ é o parametro de dificuldade do item $i$, medido na mesma escala da habilidade;

$c_{i}$ parametro que representa a probabilidade de um indivíduo com baixa habilidade responder corretamente ao item $i$ (muitas vezes referido como a probabilidade de resposta correta dada ao acaso);

$D$ é um fator de fator de escala, constante igual a 1.

A Figura 1.1 mostra uma curva característica de item quando a habilidade tem uma única dimensão (unidimensionalidade). Observe que indivíduos com altos valores para a habilidade têm maior probabilidade de responder corretamente ao item do que aqueles com baixa habilidade.

Figura 1.1 - Representaçäo gráfica de uma FCI

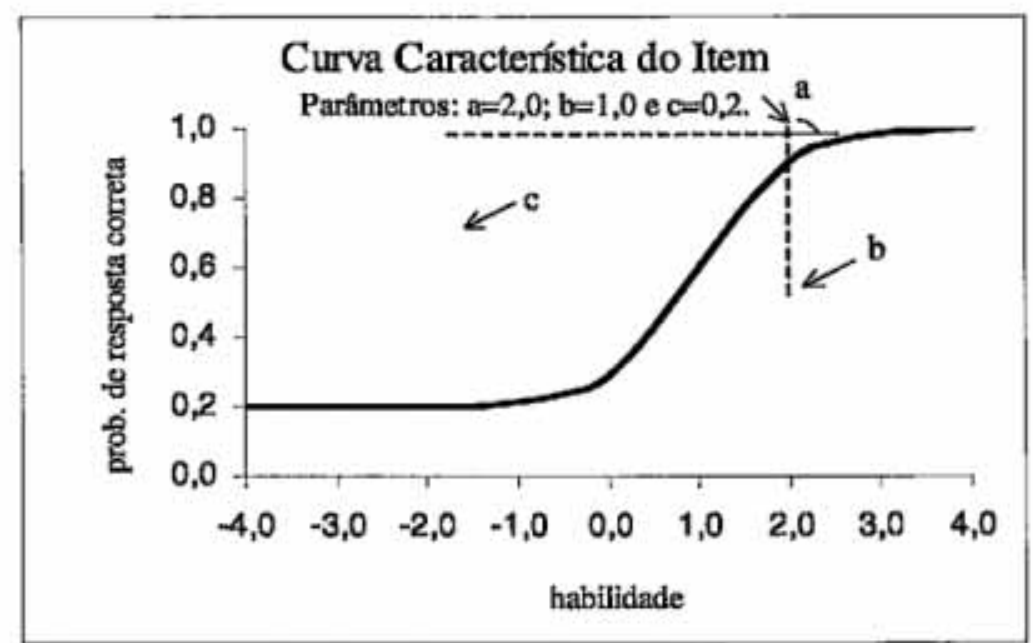

Uma abordagem aos diversos modelos unidimensionais pode ser encontrado em Hamblenton \& Swaminathan (1985) e Andrade, Tavares \& Valle (2000). 


\subsection{Suposições}

Os modelos unidimensionais têm como suposição fundamental a unidimensionalidade do teste, ou seja, supōem que o teste mede apenas um único traço latente (habilidade dominante no conjunto de itens). A independência local ou condicional fora citada em alguns trabalhos como suposição. Entretanto, com a publicação de Lord (1980), a independência não mais é vista como suposição, mas sim como conseqüência da correta determinação da dimensionalidade dos dados. A independência condicional significa que dada a habilidade do individuo, suas respostas aos diferentes itens do teste são independentes. Essa consequencia é fundamental no processo de estimação dos parâmetros do modelo. A independência condicional pode ser obtida mesmo quando os dados não são unidimensionais, desde que todas as dimensões da habilidade que influenciam a performance no teste sejam consideradas. Por exemplo, considere um teste de matemática no qual os itens exigem niveis altos da habilidade verbal (interpretação de texto). Individuos com níveis baixos dessa habilidade podem não responder corretamente aos itens mesmo possuindo níveis altos da habilidade matemática. Dessa forma, a performance no teste é influenciada por ambas as habilidades: matemática e verbal. Se um modelo unidimensional é ajustado aos dados, considerando apenas a habilidade matemática, a independencia condicional nâo pode ser considerada, pois as respostas aos diferentes itens dependera da habilidade verbal. Por outro lado, se os individuos apresentam niveis proximos de habilidade verbal, considera-se que somente a habilidade matemática influencia na performance sobre os itens; assim, a independência condicional pode ser considerada quando um modelo unidimensional é ajustado. Em testes contendo itens que exigem o conhecimento de procedimentos específicos ou estratégicos para se obter a resposta correta ou que fornecem informaçōes que ajudam a responder outros itens, a independencia condicional também não se verifica. A habilidade para detectar procedimentos especificos pode ser vista como outra dimensão além da habilidade testada.

Outras duas suposiçб̄es são: (a) o tempo para a resolução do teste é suficiente para que todos os itens possam ser respondidos por todos os individuos e (b) a ordem em que os itens sâo apresentados aos indivíduos não interfere no desempenho dos mesmos. 


\subsection{Estimação}

Uma vez determinado o modelo da TRI a ser utilizado, é necessário determinar os valores dos parametros dos itens e das habilidades dos indivíduos. Nos modelos unidimensionais, cada indivíduo é caracterizado apenas por um parâmetro, $\theta$, e para a caracterização dos itens utilizam-se de 1 a 4 parametros, dependendo do modelo utilizado. De modo geral, obtêm-se estimativas para os parâmetros do modelo com erros-padrão pequenos quando o número de itens é de pelo menos 30 e o número de respondentes para cada item é de pelo menos 300 . No processo de estimação, defrontamos- nos com 3 casos. O primeiro é quando os parâmetros dos itens são conhecidos e deseja-se apenas estimar as habilidades dos indivíduos. No segundo caso, são conhecidas as habilidades e deseja-se apenas estimar os parametros dos itens. No terceiro, nem os parametros dos itens e nem as habilidades dos individuos são conhecidos; deseja-se estimar ambos. O primeiro caso começa a ser freqüente na prática e a solução é dada empregando o método da máxima verossimilhança, através da aplicação de procedimentos interativos, como, por exemplo, o método de Newton-Raphson. Outra alternativa é a utilização de métodos bayesianos. $\mathrm{O}$ segundo caso tem apenas caráter teórico e é solucionado usando o método da máxima verossimilhança. 0 terceiro caso, provavelmente o mais encontrado na prática, é abordado de duas formas: a estimação conjunta dos parametros de itens e das habilidades dos individuos; ou em duas etapas, primeiro a estimaçăo dos itens e, em seguida, a das habilidades (Baker, 1992).

\section{$1.4 \quad$ Escala de Medidas}

Nos dois primeiros casos citados na subseção anterior, o conhecimento dos parametros (dos itens ou dos individuos) implica o conhecimento da escala em que eles foram medidos. No terceiro, não há nenhuma escala definida. Como a habilidade pode assumir qualquer valor real, os valores dos parametros que maximizam a função de verossimilhança não podem ser determinados de modo unico. É necessário, então, estabelecer uma origem, que representará a média das habilidades dos individuos na população, e uma unidade de medida, que representará o desvio-padrão das habilidades, antes do processo de estimação. As habilidades dos individuos não são observadas, mas, baseado nas respostas dos indivíduos a um conjunto de itens, é possivel estimá-las. A propriedade mais importante da habilidade é que ela não depende do particular conjunto de itens ao qual o individuo foi submetido. Essa 
propriedade possibilite uma contparuçüo difeta da tiens, testes ou performences die diferentes gruon dn individuos. $A$ habilidade pode

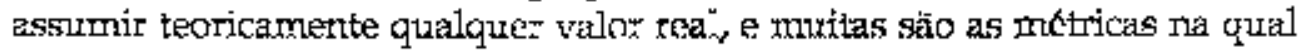
ela pode ser defirida. isuatmente, tdilizarse tuma cscala com média 0 e desvio-padräo 1. Entretanto, poder-ş-íl ustumir quaisquer outros valores, pofs o importante säo as relaços de urdem uxistentus antre os pontos da oscala. A esperificaçâo da escala elimina a nậ-identificabilidade do modolo quo ocorre devido à prodtşāo di um mosmo valor para a funçăo caracteristica do item a partir de diferentes conjtuntos de pardmetros. Uma discuskâno e desenvolvimcrto completos podem ser encontrados cm Baker (1992).

\section{Comentariog Adicionais}

Os modelos tnidimensionais da TR tom cono suposiçăg fundamental a unidimentsionalidade do teste. Fsta tuposiçăo exçge que os itens que irăo compor o teste sejam elaborados de modo a atendéla, Iintretanto, dependendo do objetivo do teste, nem simpre ibso e possiveI

A violaçào da suposição de undimentionalidade conduz, entre outras; as segutintes consequéncias neggativas: (i) a propria validade do item passa a su questionada e (ii) assumindu unt modivlo unidimensional com itens multidimensionais năo se pode gatrantir a indepundencta condicional.

Hattie (1985) Identificou mais de 30 indices sugeridos para determirtar a dimensionalidade de unia medida * os categorizou nos sieguirtes grupos:

\begin{tabular}{|l|}
\hline Grupo 1: índices baseados em padrōes de respostas; \\
\hline Grupo 2: índices baseados na fidedignidade; \\
\hline Grupo3: indices baseados na análise de componentes principais; \\
\hline Grupo 4: índices baseados na análise fatorial; \\
\hline \hline Grupo 5: indices baseados na TRI. \\
\hline
\end{tabular}

Pela cafegonizaço de Hattie (1985), a analise falorial atraves das matrizes dos coeficientes phi e das correlaçōes tetracóricas se enquadram no grupo 4 e a anílise fatorial de informaçāo plena no grupo 5. Na seçáso segunte serăo abordados essens dois grupos, com referencia especifica a essas andilises. 


\section{Análise Fatorial}

A Análise Fatorial trata do relacionamento interno de um conjunto de variáveis. Suas idéias básicas se devem, principalmente, a psicólogos como Charles Spearman, Thomson, Thurstone e Burt, que buscavam obter uma melhor compreensão para a "inteligencia".

Os testes de inteligência eram - e ainda são - montados com uma grande variedade de itens que variam em graus de memorização, habilidade verbal, habilidade matemática, entre outras. A Análise Fatorial foi desenvolvida para analisar esses testes e averiguar se a "inteligencia" era determinada por um único fator geral ou por vários fatores.

Na Análise Fatorial convencional, $p$ variáveis observadas são modeladas como funçōes lineares de um número menor, $m$, de outras variáveis continuas, denominadas variáveis latentes ou fatores. Essas variáveis são empregadas na estimação da correlação entre as variáveis observadas.

Os objetivos principais da Análise Fatorial săo:

$>$ determinar o número de fatores que fornecem um ajuste satisfatorio à matriz de correlação observada;

$>$ estimar os coeficientes de regressão das variáveis observadas nos fatores.

Com isso, almeja-se uma explicaçăo parcimoniosa do relacionamento entre as variáveis observadas.

Basicamente, o modelo fatorial é motivado pelo seguinte argumento: suponha variáveis que possam ser agrupadas por suas correlações, isto é, suponha que todas as variáveis de um grupo particular de variáveis são fortemente correlacionadas entre si, mas têm, relativamente, baixa correlação com variáveis de outros grupos diferentes. Então, é conceitual que cada grupo de variáveis representa uma única construção básica, ou fator, que é responsável pelas correlaçôes observadas. Por exemplo, correlações de testes de Inglês, Francês e Português sugerem um fator básico: "domínio verbal ou em línguas". Um segundo grupo de variáveis, representando escores em ciências exatas: Matemática e Física, por exemplo, se avaliado, corresponderia a outro fator. É esse tipo de estrutura que a Análise Fatorial procura determinar.

\subsection{Modelo Fatorial Convencional}

A Análise Fatorial é, em essência, um método para explicaçāo da variabilidade de dados através de um modelo ajustado. A matriz de covariância ou a de correlação de um número razoável de variáveis 
$X=\left(Y_{1}, \ldots, Y_{p}\right)$ é o objetivo da análise. Por hipótese, o interrelacionamento entre as variáveis pode ser explicado por um modelo de regressão linear múltiplo, com os $Y$ s como variáveis dependentes. A característica que diferencia a Análise Fatorial do modelo de regressão é que nessa os preditores, $\theta=\left(\theta_{\mathrm{L}}, \ldots, \theta_{\mathrm{m}}\right)$, não são observados, mas sim inferidos a partir dos dados. No modelo convencional de Análise Fatorial assume-se um vetor $m$-dimensional de variáveis latentes, $\theta=\left(\theta_{l}, \ldots, \theta_{m}\right)$, na população de individuos. As observações de uma amostra aleatória de $N$ indivíduos não consistem, entretanto, de valores de $\theta$, mas de valores de $p$ variáveis observadas $Y=\left(Y_{1}, \ldots, Y_{p}\right)$, onde $p>m$. É assumido, tambem, que $Y$ depende estocasticamente de $\theta$ através do seguinte sistema de equaçōes lineares:

$$
\begin{gathered}
Y_{1}=\lambda_{11} \theta_{1}+\lambda_{12} \theta_{2}+\ldots+\lambda_{I m} \theta_{m}+e_{1} \\
Y_{2}=\lambda_{21} \theta_{1}+\lambda_{22} \theta_{2}+\ldots+\lambda_{2 m} \theta_{m}+e_{2} \\
\vdots \\
Y_{p}=\lambda_{p 1} \theta_{1}+\lambda_{p 2} \theta_{2}+\ldots+\lambda_{p m} \theta_{m}+e_{p}
\end{gathered}
$$

ou, em forma matricial,

$$
\boldsymbol{Y}=\boldsymbol{\Lambda} \boldsymbol{\theta}+\boldsymbol{e}
$$

O coeficiente $\lambda_{i k}, i=1,2, \ldots, p$ e $k=1,2, \ldots, m$, é definido como a carga da $i$-ésima variável no $k$-ésimo fator, e a matriz $\Lambda$ é denominada matriz de cargas fatoriais. $\theta$ é o vetor de fatores comuns, ou, simplesmente, vetor de fatores e $\boldsymbol{e}$ é o vetor de fatores específicos ou resíduos. Sendo possível a decomposição da matriz de covariancia ou a de correlação de $Y, \Sigma$, da seguinte forma:

$$
\Sigma=\Lambda \Theta \Lambda^{\prime}+\Psi,
$$

onde $\Theta$ denota a matriz de covariancia de $\theta$, e $\Psi$ representa a matriz de covariancia do residuo $e$, as cargas fatorias podem ser obtidas de tal modo que sejam fáceis de serem exploradas visualmente ou interpretadas, sem afetar o ajuste do modelo. Esse processo é conhecido como rotação de fatores (Johnson \& Wichern, 1998; Lawley \& Maxwell, 1971).

\subsection{Modelo Fatorial para Dados Dicotômicos ou Dicotomizados}

Nesta seçăo será apresentada a extensão do modelo fatorial tradicional para dados dicotômicos ou dicotomizados. A primeira idéia foi 
estabelecer uma matriz que substitufsse a matriz de covariancia ou a de correlação para variáveis contínuas e operar de acordo com o que foi apresentado na subseção anterior. As soluções iniciais foram dadas através do uso das matrizes de coeficientes phi e de correlaçōes tetracóricas. Um outro método, denominado Análise Fatorial de Informação Plena, foi introduzido a partir do artigo de Bock \& Aitkin (1981) e será abordado na parte final da seção.

\subsubsection{O Coeficiente de Correlação Phi}

Não há impedimento para o cálculo da correlação produtomomento de Pearson $(\rho(X, Y))$ entre variáveis dicotômicas - "coeficiente phi" $i^{\prime \prime}$ como ela é chamada neste caso especial. Sua fórmula é dada por

$$
\rho(X, Y)=\frac{E\left[\left(X-\mu_{X}\right)\left(Y-\mu_{Y}\right)\right]}{\sigma_{X} \sigma_{Y}}
$$

Dessa forma, seria natural aplicar o método da subseção anterior para ajustar um modelo fatorial a uma matriz de correlação assim obtida. Entretanto, vários pesquisadores têm demonstrado os problemas inerentes a essa prática.

O principal problema é que os valores do coeficiente phi dependem não só do grau de relacionamento entre as variáveis, mas, também, da média individual de cada variável.

As Tabelas $2.1,2.2$ e 2.3 ilustram os resultados obtidos numa simulação com diferentes tamanhos de amostras para o coeficiente phi. $\mathrm{Na}$ Tabela 2.1, 8 itens foram submetidos a 5000 respondentes. Cada item é uma variável que assume os valores 1 e $0: 1$ para respostas corretas e 0 para respostas incorretas. $\mathrm{O}$ primeiro item foi respondido incorretamente por apenas um dos individuos; o segundo item foi respondido incorretamente por dois indivíduos: o que errou o primeiro item e mais um. Note que somente um individuo respondeu diferentemente os dois itens. $O$ resultado para o coeficiente de correlaçăo phi foi 0,707 . O terceiro item foi respondido incorretamente pelos dois indivíduos que erraram o item anterior e mais um; o quarto item, pelos três indivíduos anteriores e mais um. Para os itens 1 e 4, apenas 3 dos 5000 individuos apresentam respostas diferentes para estes dois itens, isso fez com que a correlação phi decrescesse para 0,50. Concluindo a interpretaçâo dos itens, o quinto foi respondido incorretamente pelos 4 individuos anteriores anteriores e mais 496 , o sexto item, pelos 500 individuos anteriores e mais 500, o sétimo item, pelos 1000 indivíduos anteriores e mais 500 e o oitavo item, pelos 1500 indivíduos anteriores e mais 500 . 
Tabela 2.1 - Correlação phi para 8 itens submetidos a 5000 respondentes

\begin{tabular}{|c|c|c|c|c|c|c|c|c|}
\hline Itens & 1 & 2 & 3 & 4 & 5 & 6 & 7 & 8 \\
\hline 2 & 0,707 & & & & & & & \\
\hline 3 & 0,577 & 0,816 & & & & & & \\
\hline 4 & 0,500 & 0,707 & 0,866 & & & & & \\
\hline 5 & 0,042 & 0,060 & 0,074 & 0,085 & & & & \\
\hline 6 & 0,028 & 0,040 & 0,049 & 0,057 & 0,667 & & & \\
\hline 7 & 0,022 & 0,031 & 0,037 & 0,043 & 0,509 & 0,763 & & \\
\hline 8 & 0,017 & 0,024 & 0,030 & 0,035 & 0,408 & 0,612 & 0,802 & 1,000 \\
\hline
\end{tabular}

Nas Tabelas 2.2 e 2.3, a mesma análise é feita para outros 8 itens submetidos a 500 e 50 individuos, respectivamente. Os itens 1, 2, 3 e 4 apresentam a mesma seqüência de respostas incorretas verificadas na Tabela 2.1, e os itens 5, 6, 7 e 8 apresentam a mesma sequencia e proporção de respostas incorretas. Nota-se facilmente a dependencia indesejável do coeficiente de correlação phi da média das variáveis envolvidas.

Tabela 2.2 - Correlação phi para 8 itens submetidos a 500 respondentes

\begin{tabular}{|c|c|c|c|c|c|c|c|c|}
\hline Itens & $\mathbf{1}$ & $\mathbf{2}$ & $\mathbf{3}$ & $\mathbf{4}$ & $\mathbf{5}$ & $\mathbf{6}$ & $\mathbf{7}$ & $\mathbf{8}$ \\
\hline 2 & 0,706 & & & & & & & \\
\hline 3 & 0,576 & 0,816 & & & & & & \\
\hline 4 & 0,498 & 0,706 & 0,865 & & & & & \\
\hline 5 & 0,134 & 0,190 & 0,233 & 0,269 & & & & \\
\hline 6 & 0,090 & 0,127 & 0,155 & 0,180 & 0,667 & & & \\
\hline 7 & 0,068 & 0,097 & 0,119 & 0,137 & 0,509 & 0,764 & & \\
\hline 8 & 0,055 & 0,078 & 0,095 & 0,110 & 0,408 & 0,612 & 0,802 & 1,000 \\
\hline
\end{tabular}

Tabela 2.3 - Correlação phi para 8 itens submetidos a 50 respondentes

\begin{tabular}{|c|c|c|c|c|c|c|c|c|}
\hline Itens & $\mathbf{1}$ & $\mathbf{2}$ & $\mathbf{3}$ & $\mathbf{4}$ & $\mathbf{5}$ & $\mathbf{6}$ & $\mathbf{7}$ & $\mathbf{8}$ \\
\hline $\mathbf{2}$ & 0,700 & & & & & & & \\
\hline 3 & 0,565 & 0,808 & & & & & & \\
\hline 4 & 0,484 & 0,692 & 0,857 & & & & & \\
\hline 5 & 0,429 & 0,612 & 0,758 & 0,885 & & & & \\
\hline 6 & 0,286 & 0,408 & 0,505 & 0,590 & 0,667 & & & \\
\hline 7 & 0,218 & 0,312 & 0,386 & 0,450 & 0,509 & 0,764 & & \\
\hline 8 & 0,175 & 0,250 & 0,309 & 0,361 & 0,408 & 0,612 & 0,802 & 1,000 \\
\hline
\end{tabular}


Quando variáveis binárias são produzidas pela dicotomização de variáveis contínuas, a escolha do ponto de corte afeta os valores do coeficiente phi. A análise fatorial feita a partir da matriz dos coeficientes phi de variáveis binárias e produzida pela mesma estrutura de correlação, mas dicotomizadas em diferentes pontos, pode equivaler-se a modelos fatoriais com diferentes estruturas e possibilitar diferentes números de fatores.

Outro problema é que o valor de uma variável dicotómica é limitado, implicando que sua regressão com qualquer variável latente contínua com intervalo infinito não pode ser linear (McDonald \& Ahlawat, 1974). Se a correlação for aplicada diretamente em variáveis dicotomicas, o modelo de análise fatorial linear dado pela Equação 2.1 fica mal especificado.

Uma alternativa ao uso da matriz de coeficientes phi é apresentada em seguida.

\subsubsection{A Correlação Tetracórica}

Diferentemente do cálculo das correlaçôes phi, onde não houve nenhuma suposição sobre as variáveis observadas envolvidas, consideramse, agora, as variáveis contínuas $Y_{t}$ e $Y_{f}$ que tem distribuição conjunta normal bivariada e que as variáveis observadas, $X_{i}$ e $X_{j}$, que assumem os valores 0 ou 1 , são resultantes dessas variáveis através de um processo de dicotomização. Nesse processo, é assumido um ponto de corte para cada uma das variáveis contínuas, denotados por $\gamma_{1}$ e $\gamma_{\text {. }}$. Os valores das variáveis $Y_{i}$ e $Y_{j}$ não sâo observados diretamente, mas, somente, se assumem valores maiores ou menores do que seus respectivos pontos de corte:

$$
\begin{aligned}
& Y_{i} \geq \gamma_{i} \text { ou } Y_{i}<\gamma_{i} \\
& Y_{j} \geq \gamma_{j} \text { ou } Y_{j}<\gamma_{j}
\end{aligned}
$$

Os valores das variáveis observadas $X_{i}$ e $X_{j}$ são supostos resultantes das variáveis continuas da seguinte forma:

$$
X_{i}= \begin{cases}1, & \text { se } Y_{i} \geq \gamma_{i} \\ 0, & \text { se } Y_{i}<\gamma_{i}\end{cases}
$$

A variável $X_{j}$ recebe tratamento análogo.

A idéia agora é inferir a correlação produto momento entre $Y_{i}$ e $Y_{j}$, $\rho\left(Y_{i}, Y_{j}\right)$, a partir da observação de $X_{i}$ e $X_{j}$. Como exemplo, poder-se-ia considerar a variável $Y$ denotando a habilidade exigida por um item e a variável $X$, a respectiva resposta ao item: 1 para resposta correta e 0 para resposta incorreta. 
Seja $\pi_{\mathrm{jj}}$ a proporção de individuos na população com $Y_{i} \geq \gamma_{i}$ e $Y_{j} \geq \gamma_{j}$. A proporçăo de individuos com $Y_{i} \geq \gamma_{\mathrm{i}}$ independentemente de $Y_{f}$, e a proporçäo de indivíduos com $Y_{j} \geq \gamma_{j}$, independentemente de $Y_{i}$, são dadas por $\pi_{1}$ e $\pi_{y}$, respectivamente.

Com as suposiçôes sobre a distribuição de $\left(Y_{i} Y_{j}\right)$, temos

$$
\begin{aligned}
\pi_{V} & \equiv \int_{i}^{\infty} \int_{j}^{\infty} f\left(y_{i}, y_{j}, \rho\right) d y_{i} d y_{j} \\
\pi_{i} & \equiv \int_{i}^{\infty} \int_{x}^{\infty} f\left(y_{i}, y_{j}, \rho\right) d y_{i} d y_{j} \\
\pi_{j} & \equiv \int_{-}^{\infty} \int_{j}^{\infty} f\left(y_{i}, y_{j}, \rho\right) d y_{l} d y_{j}
\end{aligned}
$$

onde $f\left(y_{b}, y_{j}, \rho\right)$ representa a função densidade da distribuição normal padrão bivariada, com $\rho$ representando a correlação entre as variáveis $Y_{i}$ e $Y_{j}$ :

$$
f\left(y_{i}, y_{j}, \rho\right)=\frac{1}{2 \pi \sqrt{1-\rho^{2}}} \exp \left[-\frac{y_{i}^{2}+y_{j}^{2}-2 \rho y_{i} y_{j}}{2\left(l-\rho^{2}\right)}\right] .
$$

Considerando $\pi_{\text {f }}$ a proporçăo de individuos que responderam corretamente o item $i$, mas responderam incorretamente o item $j$, e definindo $\pi_{\mathrm{ij}} \mathrm{e} \pi_{\mathrm{ij}}$ analogamente, todas as proporçōes de respondentes numa tabela de contigencia $2 \times 2$ estariam determinadas.

Quando $\gamma_{\mathrm{i}} \gamma_{\mathrm{j}}$ e $\rho$, são conhecidos, $\pi_{\mathrm{j}}, \pi_{\mathrm{i}}$ e $\pi_{\mathrm{g}}$ são determinados de forma única a partir das Equações 2.3, 2.4 e 2.5. Entretanto, o caso realista é ter conhecido $\pi_{i j} \pi_{1}$ e $\pi_{i}$ e daí determinar $\gamma_{i}, \gamma_{j}$ e $\rho$, também de forma única. Quando $\rho$ é calculado a partir das proporções da tabela de contigencia $2 \times$ 2, satisfazendo as expressōes (2.3), (2.4) e (2.5), ele ê chamado coeficiente de correlação tetracórico, que será denotado por $\rho_{i j}$ (Pearson, 1900). Se a suposição de que $\left(Y_{i}, Y_{j}\right)$ tem distribuiçăo normal bivariada é verdadeira, entäo $\rho_{i j}=\rho\left(Y_{i} Y_{i}\right)$.

Quando se observam proporçōes amostrais, $\rho_{i j}$ é estimado por $r_{\mathrm{i}}, \mathrm{o}$ coeficiente de correlação tetracório amostral. Para o cálculo de $\rho_{\text {ij }}$ ou $r_{\text {ì }}$ não há formulas fechadas; aproximações computacionais eficientes são dadas por Divgi (1979). Calculando $\rho_{i j}$ para todos os pares de variáveis, no nosso caso, itens, forma-se a matriz de correlaçōes tetracóricas.

A matriz de correlações tetracóricas amostral, $S^{*}$, é uma estimativa da matriz de correlação das variáveis $Y$ 's e, assim, procedimentos padrōes de análise fatorial podem ser empregados para estimar $\Lambda$ e $\Psi$.

Da mesma forma, do modelo convencional será assumida a existencia de $m$ variáveis latentes $\theta$. Para $p>m$ variáveis observadas (por 
exemplo, $p$ itens de um teste), assume-se, tambem, que a estrutura linear para as $p$ variáveis $Y_{i}, i=1,2, \ldots, p$, é dada por

$$
Y_{i}=\lambda_{i 1} \theta_{1}+\lambda_{i 2} \theta_{2}+\ldots+\lambda_{i m} \theta_{m}+e_{i}
$$

onde os $e_{i}$ 's são os resíduos. O contraste com a análise fatorial de variáveis observadas está no fato de que os $Y^{\prime}$ 's não são observados diretamente. Observa-se, sim, um vetor de variáveis dicotômicas $X=\left(X_{1}, X_{2}, \ldots, X_{p}\right)$ com valores determinados de acordo com o processo de dicotomização apresentado no início dessa subseção.

Com a análise fatorial através da matriz de correlaçōes tetracoricas melhora-se as estimativas para as correlações, quando comparadas com a estimação através da matriz dos coeficientes phi. Uma desvantagem resulta do fato de que, diferentemente do caso de variáveis observadas com distribuição normal, a sumarização das variáveis dicotômicas em termos da matriz de covariância não retém, conjuntamente, toda informação sobre o relacionamento dessas variáveis; somente as informaçōes individuais (percentual de acertos) e a informaçōes de pares de variáveis são usadas.

\subsubsection{Análise Fatorial de Informação Plena (AFIP)}

Nas subseçōes anteriores consideramos as estimações dos parâmetros através de métodos cujja soluçôes sâo denominadas de soluçōes de "informações limitadas", no sentido de que somente são utilizadas informações de marginais de ordens inferiores da tabela de contingência que sumariza as respostas dos individuos e, portanto, toda informação avaliada para a estimação. A análise fatorial de informaçäo plena introduzida por Bock \& Aitkin (1981) não requer o cálculo de coeficientes de correlação inter-itens e supera vários problemas presentes na análise fatorial da matriz tetracórica.

Será assumido novamente o modelo fatorial para variáveis dicotômicas apresentado na subseção anterior, através da expressão (2.6). As suposiçôes são as seguintes:

i. os resíduos $e_{1}$ seguem uma distribuição normal de média 0 e variancia $\sigma_{f}^{2}$;

ii. os resíduos são independentes entre si e $\operatorname{dos} \theta$ s;

iii. $\theta=\left(\theta_{1}, \theta_{2}, \ldots, \theta_{m}\right)$, vetor dos fatores, segue uma distribuição normal multivariada com vetor de média 0 e matriz de covariêancias $I_{m}$;

iv. $Y=\left(Y_{1}, Y_{2} \ldots, Y_{p}\right)$, vetor de variáveis pseudo-observadas, seguem uma distribuição normal multivariada com vetor de médias 0 e matriz de covariancia $\Sigma$, onde $\Sigma=\Lambda \Lambda^{\prime}+\psi$. 
Com o intuito de aproximar a teoria da resposta ao item e a análise fatorial, o leitor pode interpretar a variável $Y$ como habilidade geral do individuo e $\theta$ como o vetor de habilidades especificas.

Considera-se que a probabilidade de um individuo $j$ responder corretamente ao item $i$, condicionado ao vetor de fatores $\theta$, seja dada por

$$
\Phi_{i}\left(\theta_{j}\right)=P\left(x_{i j}=1 \mid \theta_{j}\right)=\frac{1}{\sqrt{2 \pi \sigma_{i}}} \int_{-\infty}^{\gamma_{1}} \exp \left[-\frac{1}{2}\left(\frac{\mathrm{t}-\sum_{\mathrm{k}=1}^{\mathrm{m}} \lambda_{\mathrm{ik}} \theta_{\mathrm{kj}}}{\sigma_{\mathrm{i}}}\right)^{2}\right],
$$

ou seja, $\Phi_{i}\left(\theta_{j}\right)$ é a distribuição acumulada normal padrão.

No processo de estimação da matriz $\Sigma$, a matriz das cargas fatoriais, $\Lambda$, é responsável pela determinação da dimensão do vetor de fatores $\theta$. Em outras palavras, e de modo geral, as magnitudes das cargas fatoriais indicam quantos fatores devem ser contemplados pelo modelo e quanto da variância amostral de cada variável é devida a cada fator.

Na AFIP, para a estimação das cargas fatoriais, a equação que é empregada para tal fim é função das respostas de todos os $N$ individuos submetidos ao teste ou avaliação, isto é, a equação utiliza conjuntamente a informação de todos os itens para cada um dos indivíduos.

\section{Teste de Ajuste do Modelo}

Se o tamanho da amostra é suficientemente grande, uma estatística para o teste de adequação do modelo (teste da razâo de verossimilhança), assumindo o modelo relacionado à alternativa multinomial, é dado por

$$
G^{2}=-2 \sum_{l=l}^{s} \eta \log \left(N P_{l} / \eta\right) .
$$

$\mathrm{G}^{2}$ tem, aproximadamente, distribuição qui-quadrado com $s-p(m+1)+m(m$ - 1)/2 graus de liberdade, supondo um modelo com $m$ fatores. Os graus de liberdade refletem o número de padrōes de respostas observados, menos o número de parâmetros estimados, mais o número de restrições impostas para efeito de identificação. Entretanto, quando o número de parâmetros é maior que o tamanho da amostra, as frequencias esperadas podem ser próximas de zero, tornando o teste pouco confiável.

Quando na formação da matriz de correlação há dados faltantes ("missing data"), a estatística do qui-quadrado torna-se extremamente sensfvel, no sentido de superestimação. Esse fenômeno acontece, por exemplo, quando da utilização de delineamentos por Blocos Balanceados Incompletos. Outro fato é que em pesquisas da larga escala abrangendo 
diferentes localidades, os efeitos grupais podem aumentar os valores da diferença do qui-quadrado entre dois modelos. No manual do programa TESTFACT (Wilson, Wood \& Gibbons, 1998) os autores recomendam, nos casos citados acima, dividir a estatística teste (diferença de qui-quadrados) por 2 ou 3 antes de avaliar a significancia do teste. Neste trabalho, especificamente na seçäo 6, será utilizado o número 3 como divisor e a estatística teste será denominada diferença corrigida de qui-quadrados.

A estatística teste, $G^{2}$, é um índice de falta de ajuste entre o modelo e os dados. Entretanto, seu valor não deve ser interpretado diretamente, somente a diferença dos valores da estatística entre dois modelos é interpretável. De um modo geral, na comparação entre dois modelos: $M_{1}$ com $m$ fatores e $M_{2}$ com $m+1$ fatores, se $\left(G_{1}{ }^{2}-G_{2}{ }^{2}\right)$ for positiva, o segundo modelo se adequa melhor aos dados, caso contrário, o primeiro modelo é preferivel.

A dimensionalidade na Teoria da Resposta ao Item é vista como o espaço referente ao vetor $\theta$. Os modelos unidimensionais assumem a unidimensionalidade desse vetor, ou seja, $m=1$. A análise fatorial de informação plena permite testar a significancia estatística dos fatores adicionados sucessivamente ao modelo (teste da razão de verossimilhança), e será utilizada nesse trabalho como método para a verificação da dimensionalidade do espaço do vetor $\theta$.

No programa TESTFACT encontram-se implementadas a análise fatorial de informação plena e a análise fatorial através da matriz de correlações tetracoricas.

\section{Modelos Multidimensionais}

\subsection{Introdução}

Modelos unidimensionais da Teoria da Resposta ao Item vêm sendo aplicados nos últimos anos em importantes avaliaçôes educacionais. Esses modelos têm como suposiçăo fundamental a unidimensionalidade do teste, ou seja, assumem que somente um traço latente - chamaremos sempre habilidade - é necessário para explicar a performance de um indivíduo em um teste, ou, em outras palavras, que o teste exige de forma preponderante apenas uma habilidade. Nessa medida, habilidade, incorpora-se a personalidade, o nível de motivação, o tipo de educaçăo, a ansiedade, a facilidade de "trabalhar sob pressão", os conhecimentos especificos e adjacentes relacionados ao teste e todos os outros fatores que possam vir a influenciar a performance do individuo no teste. Entre tantos fatores a 
existencia de um dominante, referido como habilidade medida pelo teste, sustenta a suposição de unidimensionalidade.

Um ponto importante é que um teste pode ser unidimensional para uma população e não ser para outra. Supondo a aplicação de um teste, medindo as habilidades matemática e verbal, a duas populações distintas de individuos, se em uma delas todos os individuos apresentam niveis altos de habilidade verbal, somente a habilidade matemática afetará a performance no teste. Na segunda população, se a habilidade verbal ocorre de maneira heterogênea, ambas as habilidades influenciam significativamente a performance dos indivíduos no teste, e assim, o teste seria bidimensional.

\subsection{Modelos Matemáticos}

A Teoria da Resposta ao Item Multidimensional (TRIM) é uma metodologia relativamente nova na modelagem do relacionamento entre as habilidades de individuos e a respectiva matriz de respostas a um conjunto de itens.

A TRIM caminha buscando o mesmo desenvolvimento da Teoria da Resposta ao Item unidimensional, mas muitas são as lacunas a serem preenchidas. Vários modelos foram propostos e alguns deles vêm sendo testados e aplicados.

Nesse trabalho será dada maior ênfase aos modelos compensatórios. Esses modelos são generalizações diretas dos modelos logísticos unidimensionais que, atualmente, estão entre os mais aplicados.

Os dados a serem tratados pelos modelos estarão representados por uma matriz de zeros e uns, correspondendo, respectivamente, a respostas incorretas e corretas aos itens. A matriz de dados é geralmente composta por $N$ linhas, referentes aos individuos, e $p$ colunas, referentes aos itens. Assim, a interseção de uma linha com uma coluna representa a resposta do $j$-ésimo indivíduo, $j=1,2, \ldots, N$, ao $i$-ésimo item, $i=1,2, \ldots, p$. As suposiçōes sobre o mecanismo que cria essa matriz de dados são as seguintes: (1) com um acréscimo em pelo menos uma das dimensões (da habilidade) medidas, a probabilidade de obter uma resposta correta a um item é crescente. Isto é frequientemente chamado de suposição de monotonicidade; (2) a função relativa à probabilidade de resposta correta é suave, no sentido de que as derivadas da função são definidas; (3) a probabilidade da combinação de respostas pode ser determinada a partir do produto das probabilidades de resposta individual, quando as probabilidades são calculadas condicionalmente a um ponto do espaço $\theta$. Essa é uma conseqüência da 
correta determinação da dimensionalidade de $\theta$ - chamada de independência condicional.

Essas suposições são consistentes para vários modelos que relacionam características de individuos e de itens.

\subsubsection{Modelo Compensatório com Acerto Casual - MC3}

A forma básica para o modelo apresentado nesta subseçäo é uma generalização direta do modelo logístico de 3 parametros (Lord, 1980), para o caso onde os indivíduos são representados por um vetor de parâmetros, ao invés de um único escalar. A forma matemática do modelo é dada por

$$
P\left(\mathrm{X}_{\mathrm{ij}}=1 \mid \theta_{\mathrm{j}}\right)=\mathrm{c}_{\mathrm{i}}+\left(1-\mathrm{c}_{\mathrm{i}}\right) \frac{1}{1+\exp \left[-\left(\mathrm{D}{a_{\mathrm{i}}}_{\mathrm{j}} \theta_{\mathrm{j}}+\mathrm{d}_{\mathrm{i}}\right)\right]}
$$

onde

$X_{i j}$ é uma variável dicotômica que assume os valores 1 , quando o $j$ ésimo individuo responde corretamente ao item $i$, ou 0 quando o $j$ ésimo individuo não responde corretamente ao item $i, \operatorname{com} i=1,2, \ldots$, p e $j=1,2, \ldots, N$;

$\theta_{f}=\left(\theta_{1 j}, \theta_{2 j}, \ldots, \theta_{m i}\right)$ representa o vetor habilidade do $j$-ésimo individuo, sendo $\theta_{k,}, k=1,2, \ldots, m$, suas habilidades especificas;

$P\left(X_{i j}=1 \mid \theta_{j}\right)$ é a probabilidade de um individuo $j$ com vetor habilidade $\theta$ responder corretamente o item $i$;

$a_{1}^{\prime}=\left(a_{i 1}, a_{i 2}, \ldots, a_{i m}\right)$ é o vetor de parametros relacionados à discriminação do item $i$;

$d_{i}$ é o parâmetro relacionado à dificuldade do item $i$, medido na mesma escala da habilidade;

$c_{i}$ é o parâmetro que representa a probabilidade de um indivíduo com baixa habilidade responder corretamente ao item $i$ (muitas vezes referido como a probabilidade de resposta correta dada ao acaso);

D é um fator de escala, constante e igual a 1.

A denominaçăo compensatório se deve ao fato de que um valor baixo da habilidade em uma das dimensões pode ser compensado por um valor alto em outra dimensão. 
A equação para o modelo define uma superfície que fornece a probabilidade de resposta correta para o item como função da posição dos indivíduos no espaço de habilidade especificado pelo vetor $\theta$. Quando há somente duas dimensōes, a forma da superfície de probabilidade pode ser representada graficamente. As Figuras 3.1 e 3.2 mostram a superfície de probabilidade para o mesmo item $i\left(a_{11}=0,9 ; a_{12}=1,5 ; d_{l}=-2,0 ; c_{i}=0,2\right)$ usando dois diferentes métodos de representação. A Figura 3.1 usa uma superfície tridimensional que enfatiza a monotonicidade do incremento natural da superfície. A Figura 3.2 mostra a superfície como um gráfico de linhas de contorno de igual probabilidade de resposta correta. Essa representação enfatiza que as linhas equiprováveis são linhas retas, e, além disso, são paralelas entre si. Essa caracteristica do modelo é resultado da forma linear do expoente do $e$ na equação do modelo.

\section{Parâmetros do modelo}

\section{Parâmetros dos individuos}

Os parametros dos indivíduos, habilidades, são os elementos do vetor $\theta_{\text {. }}$ O número de elementos requeridos para modelar adequadamente a matriz de dados é fornecido pela análise fatorial de informação plena introduzida na seção anterior. As dimensōes podem não ter interpretação clara, mas são importantes para a especificação do modelo. $O$ procedimento de rotação do espaço do vetor $\theta$ possibilita muitas vezes uma melhoria na interpretação das dimensões.

\section{Parâmetro de Discriminaçũo}

As medidas clássicas para a discriminação de itens usualmente utilizadas são as correlaçōes ponto-bisserial e bisserial. Estas medidas são usadas de um modo geral como indicadoras da qualidade do item ou para a seleção de itens na composição de um teste. Na maioria das vezes, as medidas de discriminaçăo da TRI e os conceitos relacionados à informação do item são usados com o mesmo intuito, mas estas medidas também são usadas para especificar a precisão da medida fornecida por um item em diferentes nfveis da habilidade ao longo da escala $\theta$. Tanto as medidas de discriminação do item da Teoria Clássica quanto a da TRI unidimensional são baseadas na suposiçăo de que o teste está medindo um único traço latente - definido pelo escore total ou pela habilidade $\theta$.

Nos modelos da TRI unidimensional é assumido que a probabilidade de responder corretamente a um item aumenta com o 
aumento do nível da habilidade que está sendo medida. Da mesma forma, nos modelos multidimensionais é assumido que a probabilidade de resposta correta a um item aumenta quando há um aumento em cada uma das habilidades requeridas pelo teste.

O parâmetro de discriminação de um item $i$ é dado por uma função dos elementos $a_{i k}, k=1,2, \ldots, m$ e $i=1,2, \ldots, p$, do vetor $a_{i}$. Esses elementos podem ser interpretados, muitas vezes, como $k$ parametros de modelos unidimensionais (Lord, 1980). Os elementos do vetor $\boldsymbol{a}_{i}$ estão relacionados com a inclinação da superfície de resposta do item na direção dos correspondentes eixos no espaço $\theta$. Os elementos, portanto, indicam a sensibilidade do item para diferenciar habilidades ao longo dos eixos de $\theta$. No entanto, o poder de discriminação dos diferentes itens dependem da direção estabelecida no espaço de $\theta$.

Figura 3.1 - Superfície de Resposta de um item de parâmetros

$$
a_{1}=0,9 ; a_{2}=1,5 ; d=-2,0 \text { e c }=0,2 .
$$

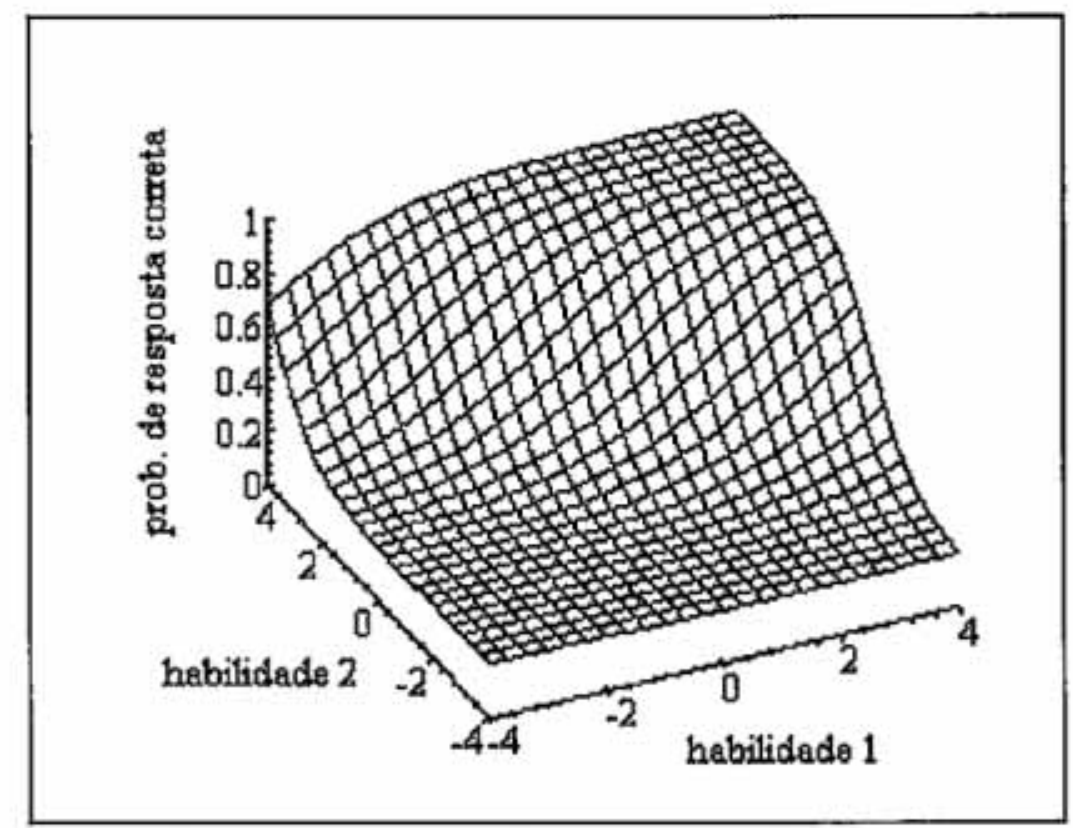


Figura 3.2 - Gráfico de Contorno da SRI dada na Figura 3.1.

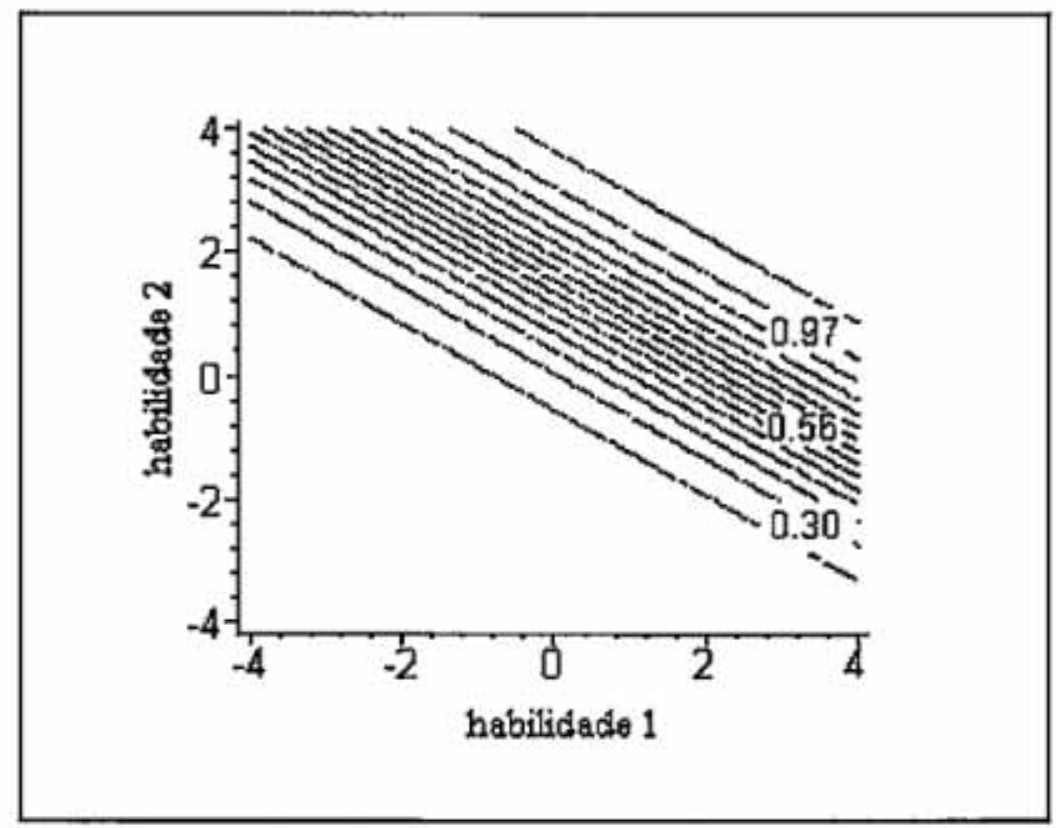

dado por

O poder de discriminação de um item $i$ multidimensional é

$$
\operatorname{DISCM}_{i}=\sqrt{\sum_{k=1}^{m} a_{i k}^{2}},
$$

onde $k$ é o número de dimensões do vetor $\theta$ e $a_{i k}$ é o $k$-ésimo elemento do vetor $a_{i}$ (Reckase, 1991).

De modo geral, o poder de discriminação de um item indica quão rápida é a transição de baixa para alta probabilidade de resposta correta a um item. Um item com alta discriminaçăo divide claramente a região espacial em duas partes, tendo apenas uma estreita região onde as probabilidades são de magnitude intermediária.

A Figura 3.3 mostra a SRI para dois itens, o primeiro com discriminação moderada e o outro com baixa discriminaçăo. Note que os dois itens não discriminam na mesma direçăo no espaço $\theta$. 
Figura 3.3 - Superfícies de Resposta de dois itens que variam na discriminação e na dimensão avaliada

Item 1: $a_{n}=1,9, a_{12}=0,7, d_{1}=c_{1}=0$ oISCM $=2,02$.

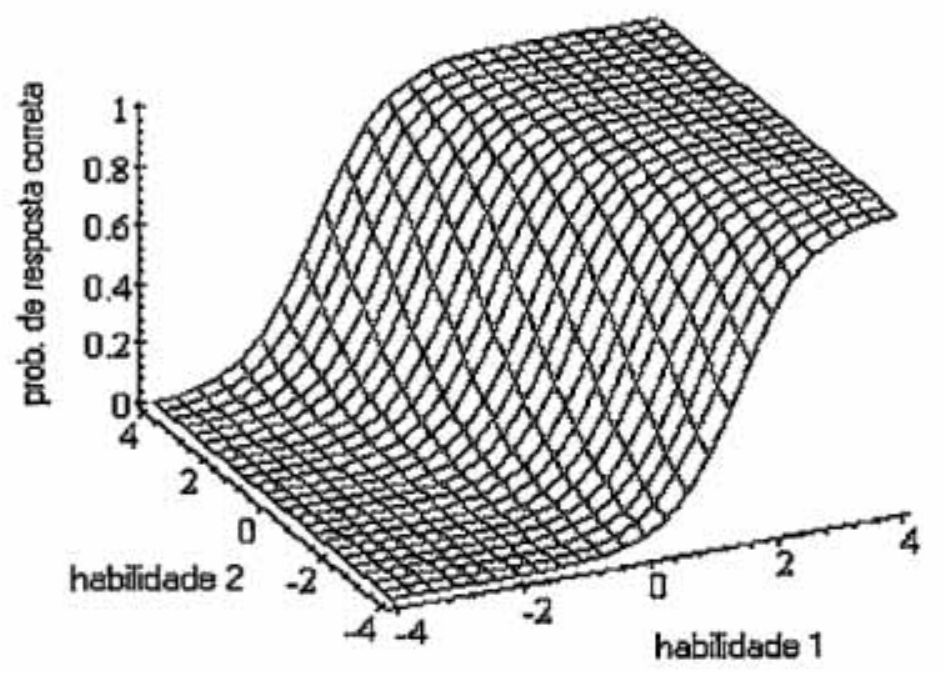

A discriminação de um item está relacionada com a inclinação da superficie de resposta ao item. A inclinaçāo difere dependendo da localização no espaço $\theta$ e da direção relativa à superfície naquela localização. Por exemplo, para o item 1 na Figura 3.3 a inclinação é quase nula no ponto $(-2,-2)$ em qualquer direção; no ponto $(2,-3)$ a inclinação é íngreme na direção aproximadamente paralela ao eixo $\theta_{1}$ (habilidade 1), e é muito baixa, ou quase nula, na direção que passa através da superfície. $O$ nfvel máximo de discriminação do item está na localização e na direção onde a inclinação é mais íngreme. $O$ poder de discriminação de um item também pode ser descrito relativo a uma particular direção no espaço $\theta$. Usando esta medida, dois itens podem ser comparados diretamente para determinar qual apresenta melhor medida para uma particular habilidade.

$\mathrm{Na}$ Figura 3.3, por exemplo, o item 2 é melhor que o item 1 para diferenciar dois individuos que possuem habilidades nos pontos $\left(\theta_{11}=1, \theta_{21}\right.$ $=0)$ e $\left(\theta_{12}=1, \theta_{22}=1\right)$ no espaço $\theta$. Note que estes dois individuos somente diferem na habilidade $2\left(\theta_{2}: \theta_{21} \neq \theta_{22}\right)$. Assim, o item 2 apresenta mais informação para medir $\theta_{2}$ na região especificada no espaço $\theta$. De fato, o item 2 apresenta uma mudança maior nas probabilidades para os dois individuos do que o item 1 , considerando a direção que é paralela a $\theta_{2}$. 
Item2: $a_{21}=0,4, a_{22}=1,2, d_{2}=2, c_{2}=0$ e $\operatorname{OrSCM}_{2}=1,26$.

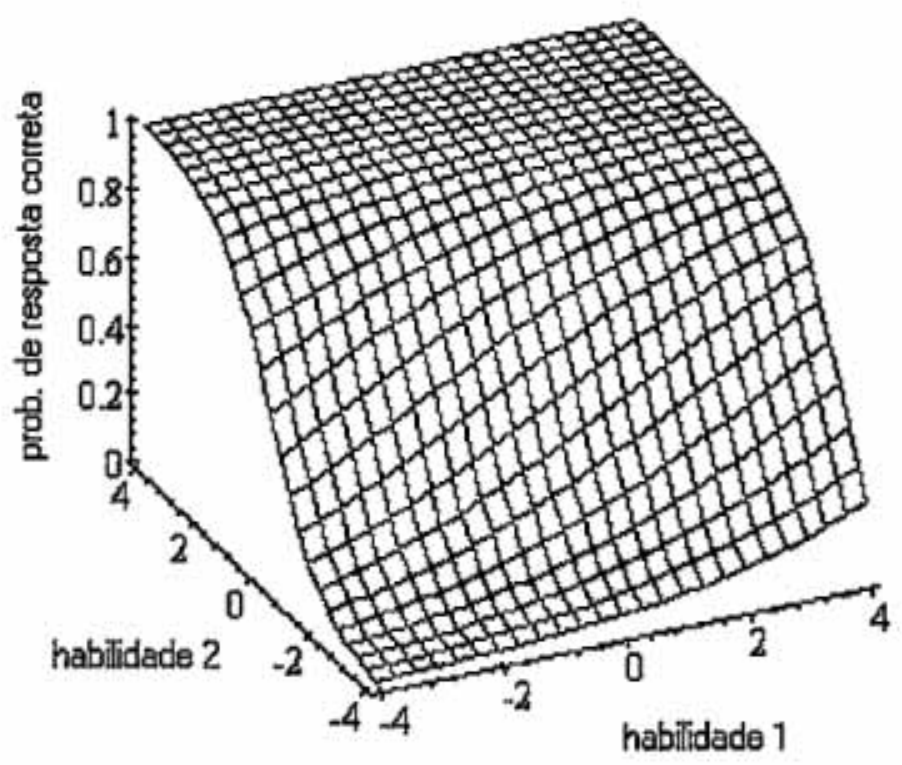

\section{Panimetro de dificuldade}

Estatísticas que descrevem caracteristicas de itens sảo comumente empregadas no processo de construção de testes. Estas estatísticas são frequientementes usadas para produzir formas equivalentes de testes ou para produzir testes com características especificas. De modo geral, essas estatísticas assumem que o item está medindo uma única habilidade. Entretanto, os itens são, geralmente, multidimensionais em algum sentido e, dependendo da intensidade das dimensões, as estatísticas unidimensionais não são apropriadas. Alguns itens medem ou exigem de forma mais dominante uma só habilidade. Para estes itens as estatísticas unidimensionais são razoáveis. Por outro lado, itens que requerem claramente mais de uma habilidade necessitam de um tratamento diferenciado, ou seja, necessitam de medidas que levem em consideração as diferentes dimensôes da habilidade.

Os problemas de matemática que envolvem um texto a ser interpretado são exemplos comuns desses tipos de itens. Ambas habilidade verbal (interpretação de texto) e habilidade matemática são necessárias ou exigidas para se obter a resposta correta. Medidas unidimensionais são 
inapropriadas para esse tipo de item. Como exemplo, poder-se-ia considerar o interesse em ordenar um conjunto de itens desse tipo segundo o parâmetro de dificuldade unidimensional. A ordenaçăo alternar-se-ia dependendo de quão intensas fossem as habilidades verbal ou matemática da amostra de individuos.

$\mathrm{Na}$ Teoria da Resposta ao Item unidimensional o parâmetro de dificuldade $b$ representa a habilidade necessária para uma probabilidade de acerto ao item igual a $(1+c) / 2$, no modelo de 3 parâmetros e, obviamente, $1 / 2$ no modelo de 2 parametros. O parâmetro $b$ é indicado pelo ponto na escala $\theta$ onde a inclinação da curva característica do item é máxima. Esse ponto coincide com o ponto de inflexão da curva.

No caso multidimensional, o parametro $d_{i}$ está relacionado à dificuldade do item. No entanto, o valor desse parâmetro não pode ser interpretado da mesma forma como no modelo unidimensional correspondente (modelo logístico de 3 parametros). O parâmetro $d_{i}$ corresponde ao termo $-a_{i} b_{i}$ no modelo unidimensional (veja Equação 1.1). Um valor que é equivalente em interpretaçăo ao parametro de dificuldade unidimensional, $b_{i}$, é dado por

$$
\operatorname{DIFICM}_{i}=\frac{-d_{i}}{\operatorname{DISCM}_{i}}
$$

DIFICM $M_{\mathrm{f}}$ indica a distância da origem do espaço $\theta$ ao ponto de maior inclinação na direção de máxima inclinação (Reckase, 1985). Esse é um significado análogo ao parâmetro $b_{i}$ do modelo unidimensional.

\section{Parâmetro de Acerto Casual}

O parametro de acerto casual, $c_{4}$, tem o mesmo significado dado no modelo logístico unidimensional de 3 parâmetros. $O$ valor desse parâmetro indica a probabilidade de resposta correta ao item por individuos com baixa habilidade em todas as dimensões.

\section{Escala de Habilidades}

De forma análoga ao caso unidimensional, faz-se necessário estabelecer uma métrica na qual serão interpretados os parâmetros do modelo. Neste trabalho, considera-se que as dimensões do vetor habilidade são ortogonais e que para cada uma delas o valor médio das respectivas habilidades é igual a 0 e o desvio-padrão é igual a 1 . No caso multidimensional também não faz diferença alguma quais valores são estabelecidos para as medidas de posição e dispersão da habilidade; o 
importante são as relações de ordem existentes entre seus pontos. Os parâmetros multidimensionais de dificuldade e de (DIFICM) discriminação (DISCM) também estão na métrica $(0 ; 1)$, ou seja, possuem média 0 e desviopadrão 1.

Os valores de DIFICM e DISCM são interpretados da mesma forma que os respectivos parâmetros no caso unidimensional. Dessa forma, esperam-se valores entre 0 e 3,0 para DISCM e valores entre $-3,0$ e 3,0 para DIFICM. O parâmetro de acerto casual depende sempre do número de alternativas de resposta para o item. Por exemplo, para um item com 5 alternativas, valores plausiveis estariam no intervalo $(0,1 ; 0,3)$, independente da escala utilizada: logistica ou normal. Os modelos multidimensionais Compensatorio e Ogiva Normal (Subseção 3.2.4) apresentam a mesma equivalência encontrada nos respectivos modelos unidimensionais, ou seja, para $D=1,702$ e o mesmo vetor de parametros os dois modelos fornecem resultados bem proximos.

\section{Suposições do Modelo}

O modelo descrito acima pressupõe que a dimensionalidade do espaço $\theta$ está adequadamente especificada. Isso nos garante a independencia condicional. Como introduzido na Seção 1, a independência condicional é fundamental no processo de estimação dos parâmetros do modelo. Outras suposiçōes são: (a) o tempo para a resolução do teste é suficiente para que todos os itens possam ser respondidos por todos os individuos e (b) a ordem em que os itens são apresentados aos individuos não interfere no desempenho dos mesmos.

\subsubsection{Modelo Compensatório sem Acerto Casual - MC2}

Quando nä̀o é possível, ou coerente, considerar a possibilidade de acerto casual ao item, o parâmetro $c$ torna-se igual a zero e tem-se o chamado Modelo Compensatório sem Acerto Casual - MC2, dado por

$$
P\left(\boldsymbol{X}_{i j}=1 \mid \theta_{j}\right)=\frac{1}{1+\exp \left[-\left(\boldsymbol{D} a_{i}^{\prime} \theta_{j}+d_{i}\right)\right]}
$$

Um exemplo seria o caso de testes com itens abertos corrigidos como certo ou errado. Os parâmetros deste modelo foram definidos na subseção anterior. 


\subsubsection{Modelos Não-Compensatórios}

O modelo não-compensatório (com acerto casual) foi desenvolvido por Sympson (1978) e é citado em Ackerman (1996). Neste modelo há um parametro relacionado à discriminação e outro à dificuldade para cada uma das dimensões. Como os termos no modelo sâo multiplicativos, a probabilidade condicional de resposta correta é limitada pela menor das probabilidades obtidas nas $m$ dimensőes do espaço $\theta$. O modelo é dado por

$$
P\left(X_{i j}=1 \mid \theta_{j}\right)=c_{i}+\left(1-c_{i}\right) \prod_{k=1}^{m} \frac{\exp \left[D a_{i k}\left(\theta_{k j}+b_{i k}\right)\right]}{1+\exp \left[D a_{i k}\left(\theta_{k j}+b_{i k}\right)\right]}
$$

onde $b_{i k}, i=1,2, \ldots, p$ e $k=1,2, \ldots, m$, é o parâmetro relacionado à dificuldade do item $i$ na dimensão $k$.

A denominaçăo não-compensatório se deve ao fato de que um nivel de habilidade alto em uma dimensão não compensa um nfvel baixo em outra dimensão. Ackerman (1996) propōe comparaçōes entre este modelo e o modelo compensatório (Equação 3.1) e cita Ackerman (1989), Lim (1993) e Hsu (1995) como referencias para a estimação dos parâmetros dos modelos não-compensatórios e compensatórios. Entretanto, programas computacionais ainda não estão disponfveis para este modelo, o que torna sua utilização restrita. Neste trabalho, esses modelos não serão vistos com maiores detalhes. $\mathrm{O}$ modelo não-compensatório sem acerto casual é obtido fazendo $c_{t}=0$.

\subsubsection{Modelos Ogiva-Normal Multidimensionais} é dado por

O modelo ogiva-normal multidimensional com acerto casual - MN3

$$
P\left(X_{i j}=\theta_{j}\right)=c_{i}+\left(1-c_{i}\right) \int_{-\infty}^{Z_{i}\left(\theta_{j}\right)} \frac{1}{\sqrt{2 \pi}} e^{-t^{2} / 2} d t,
$$

onde $Z_{i}\left(\theta_{j}\right)=a_{i 1} \theta_{1 i}+a_{i 2} \theta_{2 i}+\ldots+a_{i m} \theta_{m i}+d_{i}$. As definiçōes dos parâmetros desse modelo foram dadas na Subseçăo 3.2.1. A relaçăo entre este modelo e o modelo compensatório com acerto casual é a mesma dos respectivos modelos unidimensionais, ou seja, fazendo $D=1,702$, com o mesmo 
conjunto de parametros, os dois modelos fornecem resultados bem próximos.

Note que a Equação 3.2 possui a mesma forma da Equação 2.7. A relação entre análise fatorial e teoria da resposta ao item é tema já discutido e apresentado por alguns pesquisadores. O modelo ogiva-normal está implementado nos dois programas mais utilizados na modelagem de itens multidimensionais: NOHARM (Fraser \& McDonald, 1988) e TESTFACT (Wilson, Wood \& Gibbons, 1998). Estes programas sẫo comumente empregados para estimação de parâmetros de modelos multidimensionais.

Sem a possibilidade de acerto casual ao item, faz-se o parâmetro $c$ igual a zero e tem-se o chamado modelo ogiva-normal multidimensional sem acerto casual - MN2, dado por

$$
P\left(X_{i j}=\theta_{j}\right)=\int_{-\infty}^{Z_{i}\left(\theta_{j}\right)} \frac{1}{\sqrt{2 \pi}} e^{-t^{2} / 2} d t .
$$

\section{Aplicação a Dados Reais}

\subsection{Introdução}

O Exame Nacional do Ensino Médio (ENEM) introduziu um novo conceito de avaliação educacional no Brasil. Diferentemente de avaliações disciplinares como, por exemplo, o Sistema Nacional de Avaliação do Ensino Básico (SAEB) e o VESTIBULAR, onde cada conhecimento é medido em testes individuais, o ENEM é um exame interdisciplinar, onde os vários conhecimentos associados aos conteúdos do ensino fundamental e médio são avaliados de uma só vez por um único teste. O grande diferencial do exame pode ser atribuído aos itens que o compõem. Cada um deles é elaborado de modo a avaliar até 5 competências, mesclando os conhecimentos de diferentes disciplinas.

As análises tradicionais de itens tornaram-se, em alguns casos, obsoletas com o surgimento e desenvolvimento da Teoria da Resposta ao Item (TRI). Entretanto, a aplicaçăo dessa teoria estava restrita aos modelos unidimensionais. A grande importancia do ENEM no contexto nacional motivou o estudo dos modelos multidimensionais da TRI.

O ENEM caracteriza-se como o exame do perfil de saida da escolaridade básica e tem como um dos principais objetivos fornecer ao participante subsídios para a sua auto-avaliação (INEP, 1999; INEP 2000). Entretanto, com o aumento do número de instituições de ensino superior 
que vêm aderindo à utilização dos resultados do exame como parte de processos seletivos, o número de participantes tem aumentado significativamente.

Este seção apresenta a análise da dimensionalidade e a modelagem dos dados do Exame Nacional de Ensino Médio do ano de 1999 (ENEM99). A verificação da dimensionalidade foi feita através da Análise Fatorial de Informação Plena introduzida no Seção 2 Na modelagem dos dados foi adotado o modelo compensatório com acerto casual (MC3) apresentado na Subseção 3.2.1.

\subsection{Características do ENEM}

O Exame Nacional do Ensino Médio é aplicado desde 1998 em todo território nacional. É constituído de um teste único contendo 63 itens de múltipla escolha e uma proposta para redação. Os itens objetivos e a redação destinam-se a avaliar as competências desenvolvidas pelos participantes ao longo da escolaridade básica.

O exame tem caráter voluntário e dele podem participar, mediante inscrição, os concluintes do ensino médio, no ano de realizaçâo do exame, $\mathrm{e}$ também os que já o conclúram em anos anteriores, em qualquer de suas modalidades.

O ENEM é estruturado por uma matriz de competências que define claramente os pressupostos do exame e delineia suas características operacionais. O modelo da matriz contempla a indicação das competencias gerais proprias do aluno, na fase de desenvolvimento cognitivo correspondente ao término da escolaridade básica, associadas aos conteúdos do ensino fundamental e médio. são:

De forma resumida, as cinco competencias tratadas pelo ENEM

I. Dominar linguagens;

II. Compreender fenomenos;

III. Enfrentar situaçōes-problema;

IV. Construir argumentação;

V. Elaborar propostas.

\subsection{Dados do ENEM}

O ENEM é aplicado anualmente em todo território nacional a voluntários que concluiram ou estão em fase de conclusäo do ensino médio. A parte objetiva do exame é composta de 63 itens. A ordem dos itens e/ou as opçôes de resposta correta são alteradas com o intuito de 150 
formar 4 testes "diferentes" cada um contendo os mesmos 63 itens. Esses testes são identificados pelas cores amarela, branca, rosa e verde, e a cada um deles corresponde aproximadamente $25,0 \%$ do total de inscritos. A distribuiçẫo dos testes segue uma seqüencia alternada de cores de modo que todos eles estão presentes em todas as localidades de realização do exame.

O número de inscritos no ano de 1999 foi de 315.960 alunos em todo o Brasil. A distribuição para cada um dos 4 testes foi a seguinte: 80.251 para a cor amarela, 79.194 para a cor branca, 78.803 para a cor rosa e 77.712 para a cor verde.

Nesse trabalho serâo utilizados os dados referentes à parte objetiva do teste de cor amarela (teste amarelo). Como a distribuição dos testes segundo as cores é bem heterogênea em cada uma das localidades de aplicação do exame, tem-se uma amostra representativa da população e de tamanho significativo para a estimação dos parametros necessários à determinação da dimensionalidade dos dados e também para a estimação dos parâmetros dos itens. Para a estimação das habilidades dos participantes dispõe-se inicialmente de 63 itens, que é um numero adequado - a literatura sugere um valor maior que 30 .

\subsection{Dimensionalidade do ENEM}

O estudo da dimensionalidade do ENEM-99 foi precedido por uma análise preliminar dos 63 itens que o compõem. Estatísticas descritivas e algumas medidas da teoria clássica foram obtidas. Os resultados envolvendo o item 45 nos levaram a questionar sua utilização no estudo. Este item apresentou correlação bisserial negativa - a saber corr $b_{b}=-0,117$. Isto significa que dos individuos que o responderam corretamente a maior parte foi do grupo de individuos de pior desempenho no exame. é provável - isto merece um estudo por especialistas em itens - que a formulação do item tenha induzido os candidatos a não optar pela alternativa correta. Além da correlação bisserial, todas as correlaçôes tetracóricas envolvendo este item apresentaram valores negativos. Isto poderia comprometer as estimativas dos parâmetros necessários para a determinação da dimensionalidade. Estes resultados levaram à exclusão do item 45 do estudo. Foram excluídos também 41 indivíduos que entregaram o exame sem responder nenhum item. Dessa forma, a base de dados do ENEM utilizada neste trabalho será composta por uma matriz de respostas referente a 62 itens e 80.210 individuos.

Continuando a análise descritiva, foram obtidos os percentuais de resposta para cada item. $O$ objetivo foi verificar a não-resposta aos últimos 
itens do exame. Um percentual grande - considera-se grande qualquer valor acima de $20,0 \%$ - poderia indicar que o tempo especificado para a realização do teste foi insuficiente. Nos dados analisados o menor percentual de respostas a um item foi de $99,4 \%$, o que sugere nåo ter ocorrido problema quanto ao controle de tempo no exame. Os passos seguintes referem-se propriamente à verificação da dimensionalidade.

\section{Procedimentos}

$\mathrm{Na}$ análise da dimensionalidade dos itens o primeiro passo foi a organizaçăo do banco de dados. O programa Statistical Package for the Social Sciences - SPSS, versão 10.0 , foi utilizado para esse fim. Com ele procedeuse à formatação da base de dados de forma conveniente à utilização dos programas BILOG 3 (Mislevy \& Bock, 1990) e TESTFACT, versão 2.0.

O segundo passo foi a utilizaçäo do programa TESTFACT para determinar a dimensionalidade dos dados. Este programa tem como base teórica os artigos de Bock \& Aitkin (1981) e Dempster, Laird \& Rubin (1977). O TESTFACT vem sendo utilizado, principalmente, na verificação da dimensionalidade de testes. Nele se encontram implementadas a análise fatorial através da matriz de correlaçōes tetracóricas e a análise fatorial de informação plena. $\mathrm{O}$ programa fornece ainda estatísticas descritivas dos itens e algumas medidas utilizadas na teoria clássica. O TESTFACT permite o uso de modelos com parâmetro de acerto casual, mas não possibilita a estimação destes parâmetros; exige a entrada destes já estimados. Utilizouse, então, o programa BILOG 3 para este fim. O BILOG 3 é um programa computacional espećfico para análise de itens dicotômicos ou dicotomizados via TRI. Neste programa estão implementados os modelos unidimensionais logístico e ogiva-normal de 1, 2 e 3 parametros.

\section{Análise Fatorial de Informaçäo Plena - AFIP}

A Análise Fatorial de Informação Plena será utilizada para determinar a dimensionalidade dos dados do ENEM-99 (teste amarelo), ou seja, para a determinação do número de fatores necessários ou adequados para a explicação desses dados. Uma grande vantagem da AFIP é a possibilidade de testar a significancia estatística dos fatores adicionados sucessivamente ao modelo.

Os critérios utilizados para determinar a dimensionalidade são:

i. a diferença nos valores corrigidos de qui-quadrado (veja Subseção 2.2.3);

ii. a magnitude das cargas fatoriais após a rotação VARIMAX. 
Laros et al. (2000) utilizaram um indice de unidimensionalidade definido como a razão entre a mudança corrigida no qui-quadrado e os seus graus de liberdade. Um índice positivo maior que 2,0 implica que o modelo de $k+1$ fatores se adequa melhor aos dados do que o modelo com $k$ fatores. Indices positivos menores do que 2,0 indicam que o modelo de $k+$ 1 fatores se ajusta melhor aos dados, mas que esta melhoria não é significativa. Indices negativos indicam que o modelo de $k$ fatores se ajusta melhor aos dados do que o modelo de $k+1$ fatores. Neste trabalho tamberm será considerado tal índice - chamaremos índice de dimensionalidade (ID).

O programa TESTFACT utiliza as cargas fatoriais obtidas a partir da análise fatorial principal sobre a matriz de correlações tetracóricas (Divgi, 1979) como valores iniciais para o algoritmo EM na analise fatorial de informação plena. Este programa permite soluçôes para os principais problemas encontrados na construção da matriz de correlações tetracóricas. Essas soluções dizem respeito a possfveis correçōes antes da aplicação da análise fatorial. As correções são as seguintes: (i) correção para o acerto casual; (ii) correção para respostas omitidas; (iii) correção para obter uma matriz positiva definida e (iv) correção para evitar casos Heywood².

\section{Resultados}

Os resultados da análise para a verificação da dimensionalidade do Exame Nacional do Ensino Médio do ano de 1999 são apresentados na Tabela 4.1.

A Tabela 4.1 mostra os valores da estatística qui-quadrado, $X^{2}$, para os modelos de 1 a 5 fatores com os respectivos graus de liberdade, $g l$, as diferenças dos qui-quadrados, $X^{2}$ dif, entre um modelo de $k$ fatores e outro de $k+1$ fatores, $k=1,2,3,4$, os graus de liberdade para essas diferenças, os valores corrigidos das diferenças dos qui-quadrados, $X^{2}{ }_{\text {difforr }}$ e o índice de dimensionalidade, ID.

Foram ajustados sucessivamente os modelos de 1 a 5 fatores. Para cada fator adicionado ao modelo a estatística $X^{2}$ dffeorr foi calculada. Até o último modelo ajustado, modelo de 5 fatores, esta estatística apresentou significancia, ou seja, houve melhoria no ajuste do modelo aos dados.

\footnotetext{
$2 \mathrm{Na}$ análise fatorial de informaçäo plena, esses casos caracterizam-se quando um ou maís parâmetros a aumentam continuamente com o aumento do número de ciclos do algoritmo EM.
} 
Tabela 4.1 - ligtatisticas para o Número de Fatores do Modelo para o ENEM - 99

\begin{tabular}{|c|c|c|c|c|c|}
\hline & \multicolumn{5}{|c|}{ Número de Fatores do Modelo } \\
\hline & 1 & 2 & 3 & 4 & 5 \\
\hline $\bar{x}^{2}$ & $4.006 .317,82$ & $3.992 .022,79$ & $3.981 .784,75$ & $3.976 .992,41$ & $3.974 .241,79$ \\
\hline gi & 80.081 & 80.020 & 79.960 & 79.901 & 79.843 \\
\hline$x^{2}$ dit & & $14.295,03$ & $10.238,04$ & $4.792,34$ & $2.750,63$ \\
\hline gles & & 61 & 60 & 59 & 58 \\
\hline$X^{2}$ delogrt & & $4.765,01$ & $3.412,68$ & $1.597,45$ & 916,88 \\
\hline ID & & 78,11 & 56,88 & 27,08 & 15,81 \\
\hline
\end{tabular}

Observe na T'abela 4.1 que os valores de $X^{2}$ diminuen a medida em que săo actercentados fatores ao modelo. Consequtentementè as diferenças corrigidas tamben diminuem, variando de forma decrescente de 4.765,01 a 916,88. A menor degtas difexenças corresponde a diferença entre os valores de $X^{2}$ dos modelos de 4 e 5 fatores dividida por 3 (veja Subseçăo 22.3: Teste de Ajuste do Modelo).

Segundo o indice de dimensionalidade, $I D$, também calculado para cada fator adiciongdo ao modelo, a conclusăo is a mesma. Os f́ndices decrescen de 78,11 (valor referentie ass modelos de 1 e 2 fatores) ate 15,81 (valor referente aos modelos de 4 e 5 fatores). liste último valor ainda esta ber acima do valox crítico 2,0 citado na seçâo anterior, indịcando a significancia do modelo de 5 fatores.

O segundo criterio utilizado foi a analise das cargas fatoriais. Estas cargas são apresentadas no Aptndice. As cargas fatoriais possibilitam informar o quanto da variancia de cada variavel (item) é explicada por cada fator e tambem quats itens se relacionam a cada fator - quanto maior a carga fatorial melhor a a relagäo entre item e fator. Neste trabalho contidera-se que cargas fatoriais inferiores a 0,20 nato contribuem para a merhturaçato dos respectivos fatores. Analisando as cargas fatoriais (apos rotaçăo VARMMAX), para cada vm dos 3 primeires fatores, nota-se que a grande majoria delas apresenta valores expressivos. Isto indica que quase todos os itons estao relacionadas a pelo menos um dos tres fatores. Por exemplo, os iteris 13,14 e $I 5$ está bem relacionedos aos fatores 1,2 e 3. Já as itens I21 e J27 se relacionam melhor aos fatores l e 3. Para a mensuraça do quarto fator cmtribuem quase $50 \%$ dos itens. Ao quinto fator estao relacionados apenas os ifens $19,128,729,136$ e 143 .

Un critgrio complementer para a dectsa do númaro de fatores no modelo setá o percentual de explicação da variancia das variáveris (iterns) 
devida a cada fator. A Tabela 4.2 mostra esses percentuais. $O$ valor acumulado até o quinto fator foi de $45,33 \%$. No caso dos fatores não rotacionados, o primeiro fator é responsável por $39,85 \%$ e os demais fatores contribuem com percentuais inferiores a 2,06\%. Sob essa analise poder-se-ia sugerir a utilização de um modelo de 1 fator (modelo unidimensional). Entretanto, a propria estrutura do exame sugere um modelo multidimensional. Objetivando uma melhor interpretação, os fatores foram submetidos à rotação VARIMAX. Com a rotação, os três primeiros fatores passaram a apresentar percentuais muito proximos. $O$ percentual acumulado dos três primeiros foi de $38,54 \%$. O quarto fator contribuiu com $5,55 \%$ e o quinto fator com $1,24 \%$. Estes resultados retratam coerentemente os resultados obtidos anteriormente pela análise das cargas fatoriais.

Tabela 4.2 - Percentual da Variância Explicada por cada Fator do Modelo

\begin{tabular}{|l|r|r|r|r||c|}
\hline \multicolumn{7}{c|}{ Fatores } & & \\
\hline & \multicolumn{1}{|c|}{$1^{\circ}$} & $2^{\circ}$ & $3^{\circ}$ & \multicolumn{1}{c|}{$4^{\circ}$} & $5^{\circ}$ \\
\hline Fator(es) năo rotaclonado(s) & 38,85 & 2,05 & 1,54 & 1,06 & 0,82 \\
\hline \hline Fator(es) após roteçäo varimax & 13,49 & 12,31 & 12,74 & 5,55 & 1,24 \\
\hline
\end{tabular}

A decisão final sobre o número de fatores do modelo, isto é, a dimensionalidade do referido instrumento de avaliação (ENEM), deve, entretanto, ser tomada em conjunto com os especialistas que o construíram.

\subsection{Análise dos Itens do ENEM}

Nesta seção é apresentado o resultado da estimação dos parâmetros dos itens do ENEM-99. O modelo adotado foi o MC3 (veja Subseção 3.2.1). Os itens são caracterizados pelos parametros de acerto casual (c), discriminação (DISCM) e dificuldade (DIFICM). No apêndice estes 3 parâmetros sảo apresentados para cada um dos 62 itens do exame. Os resultados estăo representados graficamente na Figura 4.1.

Com exceção do item 14, com parâmetro de discriminação igual a 3,84 , todos os demais itens apresentaram discriminação no intervalo esperado de 0 a 3,00 . Para o parametro de dificuldade DIFICM, todos os itens apresentaram valores no intervalo $-3,00$ a 3,00 , mais precisamente entre $-1,48$ e 2,48. Na Figura 4.1 vê-se claramente que os itens estão bem distribuidos segundo esses dois parâmetros. 
Figura 4.1 - Representação gráfica dos parâmetros DIFICM e DISCM para os 62 itens do ENEM - 99

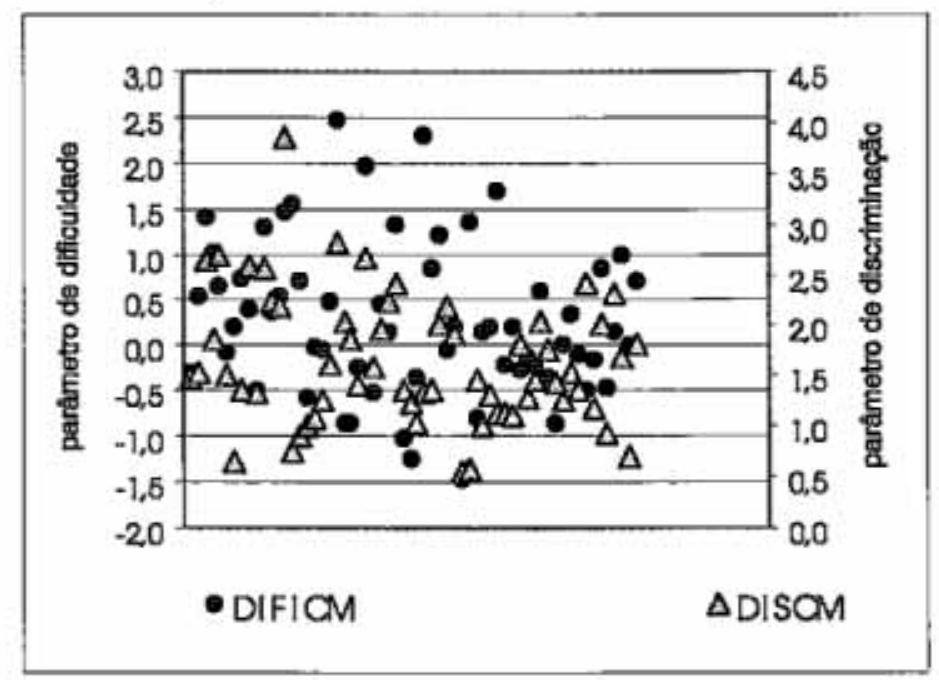

Os parâmetros $c$, $d$ e $a$ 's do modelo $\mathrm{MC} 3$ também estão presentes no Apêndice. Estes resultados permitem identificar, por exemplo, quais itens são comparáveis segundo seus parametros de dificuldade. Diferentemente do caso unidimensional, nem sempre a comparação é possivel ou adequada (veja Seção 3). Para exemplificar, considere dois grupos de itens. O primeiro deles formado pelos itens $I 1$ e $I 8$ e o segundo composto pelos itens I28 e 129. Analisando os valores dos parametros do modelo (especificamente os parametros a's) é razoável comparar as dificuldades para os itens II e I8. As dificuldades para os itens $I 28$ e $I 29$ tamberm são comparáveis. Entretanto, as dificuldades entre itens de grupos diferentes não são comparáveis, pois os grupos não estâo medindo as mesmas habilidades (fatores). Os itens $I 28$ e $I 29$ estão relacionados aos fatores $1,2,3$ e 5, enquanto os itens $I 1$ e $I 8$ estão relacionados apenas aos fatores 1 e 2 . Com esta análise é possfvel estruturar testes que possam medir combinaçöes de habilidades em vários níveis de dificuldade.

\section{Comentários e Sugestões Finais}

A aplicação e o desenvolvimento da Teoria da Resposta ao Item (TRI) em muito dependem da disponibilização de programas computacionais que possam facilitar ou viabilizar sua utilização. $\mathrm{Na}$ Europa e nos Estados Unidos, a TRI é uma ferramenta comumente utilizada em diversas áreas profissionais, entre elas a Educacional. No 
Brasil, a TRI é bem recente. Sua primeira aplicação foi na análise do Sistema Nacional de Avaliação Básica (SAEB), em 1995. Desde então, os órgãos governamentais, através do Ministério da Educação (MEC), vêm valorizando e incentivando o uso dessa teoria nas avaliações educacionais brasileiras. Entre outras avaliações podemos citar o Sistema de Avaliação de Rendimento Escolar do Estado de São Paulo (SARESP) e a Avaliação das Escolas Públicas do Estado do Rio Grande do Norte.

Este trabalho é pioneiro na utilização da TRI multidimensional no Brasil. Este estudo inicial possibilitou avaliar sob este novo enfoque o Exame Nacional do Ensino Médio caracterizado como um exame interdisciplinar e que por isto sugeria a utilização de modelos onde a habilidade fosse expressa por mais de uma dimensão. Até então, as aplicações se restringiam às avaliaçōes unidimensionais.

Relativamente a outras áreas da psicometria, a TRI multidimensional ainda está na sua "infancia". Vários problemas precisam ser solucionados e metodologias ainda precisam ser desenvolvidas para ajudar na solução desses problemas. Contudo, os estudos têm ratificado que o relacionamento entre itens e individuos é bem mais complexo que o suposto nos procedimentos psicométricos usuais.

Entre as lacunas a serem preenchidas podemos citar, por exemplo, a questão do efeito sobre o escore total quando da inclusão de itens medindo múltiplas dimensōes no teste (Reckase, 1989). Alguns trabalhos foram feitos no sentido de compreender melhor esta questão, mas esta pesquisa ainda está no seu início. Outro ponto pouco explorado diz respeito à equalização utilizando modelos multidimensionais. Esta é uma área de grande necessidade de pesquisa porque muitos dos testes educacionais utilizados, provavelmente, avaliam a habilidade em mais de uma dimensão e o estabelecimento de uma métrica comum no sentido de comparar os resultados desses testes ainda não está definida.

Neste trabalho apresentamos alguns dos modelos multidimensionais citados na literatura. Outros modelos estão presentes em algumas referencias citadas, por exemplo, Linden et al. (1997). Há vários outros modelos ainda pouco explorados, como, por exemplo, a versão multidimensional para modelos de respostas a itens politomicos, os modelos multidimensionais longitudinais e os modelos multidimensionais multivariados. Tavares (2001) e Matos (2001) desenvolveram, respectivamente, modelos longitudinais e modelos multivariados unidimensionais.

Outra área que necessita de pesquisas adicionais é a de estimação dos parametros dos modelos multidimensionais. Embora bons programas existam (por exemplo, TESTFACT e NOHAM), pouco é conhecido sobre o 
número de itens $\mathrm{e} / \mathrm{ou}$ de respondentes necessários para a especificação adequada da dimensão do espaço latente. Perguntas como: (i) Qual é o relacionamento entre tamanho da amostra, a heterogeneidade da população de indivíduos e o número de dimensões que pode ser identificada? e (ii) $O$ que significa dizer que duas dimensőes são altamente correlacionadas mas distintas? ainda necessitam de estudos para que sejam respondidas. Sem dúvida, essa é uma área rica para futuras pesquisas.

A aplicação feita neste trabalho considerou apenas os resultados de um dos 4 testes do Exame Nacional do Ensino Médio. Como a "diferença" nos testes está na ordem de apresentação dos itens e/ou das alternativas de respostas, uma questão importante seria avaliar se haveria mudanças significativas nos resultados obtidos para a análise da dimensionalidade dependendo do teste utilizado.

Outro ponto que necessita de pesquisas adicionais refere-se ao estabelecimento de critérios para a qualidade do item multidimensional. No caso unidimensional, um exemplo de item de má qualidade é aquele com parâmetro de discriminação negativo ou com valor positivo baixo. Para o caso multidimensional, as aplicações estão no início e um estudo detalhado faz-se necessário.

Por fim, gostariamos de ressaltar que a aplicação apropriada dessa teoria exige fundamentalmente a integração de especialistas das áreas de estatística e educação. 


\section{Apêndice}

Este Apêndice apresenta as cargas fatoriais, antes e apos a rotação VARIMAX, fornecidas pelo programa TESTFACT. Os valores para os parâmetros c, d, a's, DIFICM e DISCM para cada um dos itens, segundo o modelo MC3, são apresentados em seguida.

\section{Resultados do programa TESTFACT: cargas fatoriais não rotacionadas}

\begin{tabular}{|c|c|c|c|c|c|c|}
\hline-0 & +18 & 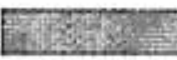 & Tas & FATORES & 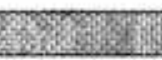 & 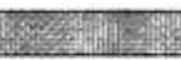 \\
\hline E: & TIEM & 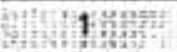 & 2 & 3 & 4 & 5 \\
\hline 1. & II: & 0.597 & 0.111 & 0230 & 0.710 & 0.015 \\
\hline 2 & 12 & 0.803 & 0.127 & -0242 & -0.053 & 0.091 \\
\hline 3 & 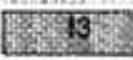 & 0.784 & 0.022 & 0780 & 0.165 & 0.181 \\
\hline 4 & 14 & 0.676 & 0.111 & 0158 & -0.114 & 0.191 \\
\hline 5 & 15 & 0.819 & 9.113 & 0.098 & $0 \times 118$ & -0.124 \\
\hline 6. & 18 & 0.628 & 0.027 & -0.021 & -0.049 & -0.204 \\
\hline 7 & 17 & 0.332 & 0.101 & 0.016 & -0.042 & 0.055 \\
\hline 8 & 18 & 0.577 & -0.127 & -0.155 & $-0,102$ & -0.068 \\
\hline 8 & 19 & 0.794 & 0.011 & 0,142 & 0.055 & 0.208 \\
\hline 10 & 110 & 0.508 & -0.320 & 0.017 & 0.124 & 0.084 \\
\hline 11 & 111 & 0.794 & 0243 & 0.023 & 0.063 & 0.017 \\
\hline 12 & 112 & 0.779 & 0.122 & -0.004 & -0.07 & 0.081 \\
\hline 13 & 78 & 0.756 & 0.164 & 0.085 & 0.121 & 0.039 \\
\hline 14 & 114 & 0.893 & 0.131 & -0.026 & $-0,069$ & 0,128 \\
\hline 15 & 155 & 0.345 & 0,082 & 0.184 & 0.056 & 0,007 \\
\hline 16 & 116 & 0.466 & -0.013 & 0.010 & $-0,019$ & 0.112 \\
\hline 17 & 118 & 0.482 & 0139 & 0,056 & 0.051 & 0.070 \\
\hline 18 & 118 & 0.514 & -0.101 & -0.078 & 0.071 & 0,050 \\
\hline 19: & Hig: & 0.642 & 0.074 & 0236 & 0.004 & 0.035 \\
\hline 20 & 129 & 0.646 & 0.216 & 0.055 & 0.046 & 0,006 \\
\hline 27 & 212 & 0787 & 0.325 & 0.021 & 0,075 & 0.005 \\
\hline 22 & 122 & 0.689 & -0.268 & 0.137 & 0.140 & 0.043 \\
\hline 23 & 123 & 0.647 & 0.308 & -0.059 & 0.148 & 0069 \\
\hline 24 & 124 & 0.615 & 0.117 & $-0,122$ & 0,001 & 0,065 \\
\hline 25 & 125 & 0.820 & 0.140 & $0,0,25$ & 10.039 & 0.032 \\
\hline 26 & 128 & 0.676 & 0.014 & -0.07 & 0.018 & 0.006 \\
\hline
\end{tabular}




\begin{tabular}{|c|c|c|c|c|c|c|}
\hline 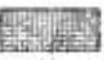 & 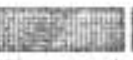 & 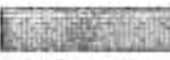 & 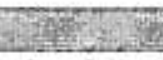 & FATORES & 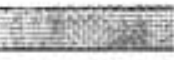 & 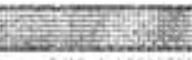 \\
\hline & ITEM & 1 & 2 & 3 & 4 & 5 \\
\hline 27 & 127 & 0.705 & 0.240 & -0.074 & 0.010 & -0.101 \\
\hline 28 & 128 & 0.764 & -0.005 & 0.027 & -0.075 & 0.206 \\
\hline 29 & 129 & 0.771 & 0.044 & -0.007 & -0.140 & 0,229 \\
\hline 30 & 130 & 0.578 & 0.091 & -0.189 & 0.053 & 0.072 \\
\hline 31 & 139 & 0.523 & 0.286 & 0.008 & 0.014 & -0.024 \\
\hline 32 & 132 & 0.482 & 0.148 & 0.100 & -0.006 & 0,063 \\
\hline 33 & 138 & 0.593 & 0.081 & 0.098 & 0.048 & 0.714 \\
\hline 34 & 134 & 0.553 & 0.139 & 0.256 & -0.015 & 0.014 \\
\hline 35 & 135 & 0,743 & 0.696 & 0.126 & 0.017 & 0.067 \\
\hline 36 & 136 & 0.765 & 0.033 & 0.179 & 0.000 & 0.131 \\
\hline 37. & 137 & 0.664 & 0.019 & 0.324 & -0.022 & 0.109 \\
\hline 38 & 138 & 0.278 & 0.030 & 0.077 & 0.064 & -0.085 \\
\hline 39 & 139 & 0.297 & -0.000 & -0.130 & 0.023 & 0.020 \\
\hline $40^{\circ}$ & 140 & 0.622 & -0.183 & 0.021 & -0.006 & -0.037 \\
\hline 41 & 141 & 0,502 & 0.037 & 0,024 & 0.013 & 0.064 \\
\hline 42 & 142. & 0.549 & -0.249 & -0.054 & -0.025 & 0.080 \\
\hline 43 & 443 & 0.517 & 0.028 & -0.006 & 0.068 & 0.183 \\
\hline 44 & 144 & 0.513 & 0.084 & 0.190 & 0.057 & 0.015 \\
\hline 45. & 168 & 0.523 & 0.098 & 0.088 & 0.066 & 0.004 \\
\hline 46 & 147 & 0.685 & 0.132 & -0.131 & 0.157 & 0.028 \\
\hline 47 & M8. & 0.574 & -0.181 & 0.025 & 0,038 & -0.028 \\
\hline 48 & 140 & 0.504 & 0.190 & 0.187 & 0.022 & $-0,047$ \\
\hline 49 & 150 & 0.759 & 0.065 & 0.014 & 0.052 & 0.086 \\
\hline 50. & 151 & 0.670 & -0.039 & -0.060 & 0.251 & -0.028 \\
\hline 51 & 152 & 0.578 & 0.065 & $0.151=$ & 0.228 & 0.011 \\
\hline 52 & 153 & 0.551 & -0.190 & 0.056 & 0,098 & 0.027 \\
\hline 53. & 154. & 0.619 & -0.043 & 0.215 & 0.127 & 0.029 \\
\hline 54 & 165 & 0.567 & -0.045 & 0.054 & 0.219 & -0.124 \\
\hline 56 & 156 & 0.762 & 80068 & 0.011 & 0.287 & 0.088 \\
\hline 56 & 167 & 0.520 & 0.023 & 0.217 & 0.083 & 0.043 \\
\hline 57 & 158: & 076 & 0.005 & 0,072 & 0.056 & 0.048 \\
\hline 58 & 158 & 0.414 & -0.123 & -0.087 & 0.189 & 0.042 \\
\hline 59 & 160 & 0.721 & .0 .165 & 0.142 & 0,083 & -0.046 \\
\hline 60 & 161 & 0.858 & 0.119 & -0.090 & 0.479 & $-0,078$ \\
\hline 61 & 162 & 0.345 & -0.019 & -0.040 & 0.163 & 0,002 \\
\hline 62 & 163 & 0.670 & .0 .264 & -0.080 & 0,067 & 0.002 \\
\hline
\end{tabular}


Resultados do programa TESTFACT: cargas fatoriais após rotação VARIMAX

\begin{tabular}{|c|c|c|c|c|c|c|}
\hline & & & & FATORES & & \\
\hline 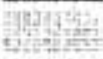 & ITEM & 1 & 2 & 3 & 4 & 5 \\
\hline 1. & 9 & 0.438 & 0.452 & 0.122 & 0.126 & 0.089 \\
\hline 2 & 12 & 0.567 & 0.260 & 0.188 & 0.153 & -0.022 \\
\hline 3 & 13 & 0.372 & 0.445 & 0.589 & 0,115 & -0.107 \\
\hline 4 & 14 & 0.363 & 0.305 & 0.538 & 0.111 & -0.130 \\
\hline 5 & 75 & 0.552 & 0,369 & 0.480 & 0.160 & 0.042 \\
\hline 6 & 16 & 0.397 & 0.342 & 0.340 & 0.175 & 0.138 \\
\hline 7 & 17 & 0.133 & 0.269 & 0.164 & 0.089 & -0.017 \\
\hline 8 & 18 & 0.375 & 0.452 & 0.163 & 0.128 & 0.003 \\
\hline 9 & 19 & 0.532 & 0.419 & 0,327 & 0214 & 0.294 \\
\hline 10 & 110 & 0.156 & 0.563 & 0.172 & 0.104 & -0.020 \\
\hline 11 & 113. & 0.560 & 0.241 & 0,532 & 0177 & 0.090 \\
\hline 12 & 112 & 0.515 & 0.343 & 0.467 & 0.181 & -0.004 \\
\hline 13 & 113 & 0.300 & 0551 & 0843 & 0.160 & 0.118 \\
\hline 14 & 114 & 0.599 & 0.399 & 0.513 & 0.229 & -0.039 \\
\hline 15 & 915 & 0.127 & 0,119 & 2360 & 0.046 & 0.079 \\
\hline 16 & 116 & 0.236 & 0.245 & 0.250 & 0.133 & 0.169 \\
\hline 17 & 177 & 0.175 & 0379 & 0.264 & 0.136 & -0.017 \\
\hline 18 & 18 & 0.292 & 0.373 & 0.192 & 0.123 & 0.109 \\
\hline 19 & 119 & 0.489 & 10250 & 0.134 & 0.190 & 0.028 \\
\hline 20 & 120 & 0.511 & 0.188 & 0.382 & 0.150 & 0.067 \\
\hline 21 & 121: & 0.602 & 0.858 & 0.556 & 0.153 & 0.074 \\
\hline 22. & 122 & 0.353 & 0.622 & 0.194 & 01144 & 0.128 \\
\hline 23 & 123 & 0.268 & 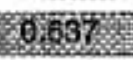 & 0.221 & 0.129 & $0.0 \mathrm{~m}$ \\
\hline 24 & 124 & 0.475 & 0.235 & 0.276 & 0.197 & 0.119 \\
\hline 25 & 225 & 0.615 & 0 & 0.397 & 0.231 & 0.053 \\
\hline 26 & 126 & 0.435 & 0.355 & 0.312 & 0.214 & 0.067 \\
\hline 27 & 127 & 0.569 & 0.198 & 0.404 & 0.207 & -0.032 \\
\hline 28 & 128 & 0.404 & 0.408 & 0.437 & 0.180 & 0.283 \\
\hline 29 & 129 & 0.468 & 0.394 & 0.439 & 0.715 & 0305 \\
\hline 30 & 130 & 0.474 & 0.225 & 0.189 & 0.238 & 0.137 \\
\hline 31 & 131 & 0,164 & 0.488 & 0.191 & 0.201 & 0,040 \\
\hline 32 & 132 & 0.276 & 0.125 & 0.385 & 0.132 & 0.104 \\
\hline
\end{tabular}

Estudios em Avaliaçđo Educacional, n. 25, jan-jun/2002 


\begin{tabular}{|c|c|c|c|c|c|c|}
\hline$b^{2}$ & 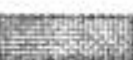 & Pronese & 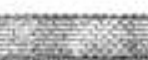 & FATOAES & 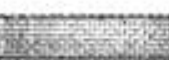 & \\
\hline & ITEM & 1 & 2 & 3 & 4 & 5 \\
\hline 33 & 138 & 0.308 & 0.245 & 0.426 & 0.136 & 0.168 \\
\hline 34 & 134 & 0.218 & 0.163 & 0.542 & 0.144 & 0.056 \\
\hline 35 & 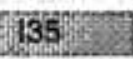 & 0.547 & 0.325 & 0.337 & 0.227 & 0.135 \\
\hline 36 & 136 & 0.314 & 0.344 & 0.554 & 0.238 & 0.200 \\
\hline 37 & 137 & 0.170 & $0 \$ 303$ & 0.614 & 0.183 & 0.163 \\
\hline 38 & 138 & 0.116 & 0.103 & 0.213 & 0.151 & -0.059 \\
\hline 39 & 139 & 0.244 & 0.181 & 0.058 & 0.129 & 0.017 \\
\hline 40 & 140 & 0.243 & 0.472 & 0.293 & 0.230 & 0.033 \\
\hline 49 & 141 & 0.242 & 0.288 & 0.278 & 0.159 & 0.116 \\
\hline 42 & 142 & 0.211 & 0.488 & 0.176 & 0.195 & 0.147 \\
\hline 43 & 143 & 0283 & 0.213 & 0.273 & 0.225 & 0.236 \\
\hline 44 & 144 & 0.197 & 0.168 & 0.443 & 0.207 & 0.058 \\
\hline 45: & 9146 & 0.174 & 0.323 & 0.310 & 0.247 & 0.059 \\
\hline 46 & 147 & 0.607 & 0.220 & 0.295 & 0.368 & 0.043 \\
\hline 47 & 148 & 0.207 & 0.432 & 0.266 & 0.252 & 0.037 \\
\hline 48 & 149 & 0.114 & 0.442 & 0.400 & 0.241 & 0.014 \\
\hline 49. & 150 & 0.432 & 0.322 & 0.435 & 0.293 & 0.167 \\
\hline 50 & 151 & $0.35 \%$ & 0.311 & 0.274 & 0.470 & 0.047 \\
\hline 61. & 152 & 0.409 & 0.203 & 0.188 & 0.409 & 0.056 \\
\hline 52 & 163 & 0.156 & 0.400 & 0.266 & 0.299 & 0.089 \\
\hline 53 & 154 & 0.164 & 0.298 & 0.470 & 0.323 & 0.086 \\
\hline 54 & 155 & 0.230 & 0.270 & 0.309 & 0.406 & -0.063 \\
\hline 55 & (156: & 0337 & 0.365 & 0.365 & 0.536 & 0.046 \\
\hline 56 & 157 & 0.152 & 0.214 & 0.445 & 0.243 & 0.002 \\
\hline 57 & 158 & 0.402 & 0.371 & 0.417 & 0.306 & 0.126 \\
\hline 58 & 159 & 0.189 & 0.258 & 0,094 & 0.334 & 0,093 \\
\hline 59 & 160 & 0.244 & 0.500 & 0.462 & 03366 & 0.085 \\
\hline 60 & 161 & 0.459 & 0.209 & 0.305 & 0.381 & -0.006 \\
\hline 61 & 162 & 0.181 & 0.748 & 0130 & 0.273 & 0.041 \\
\hline 62 & 163 & $0.2 \pi$ & 0.543 & 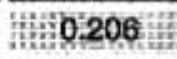 & 0,327 & 0.085 \\
\hline
\end{tabular}
form $P V E_{m}=\left(\sum_{i=1}^{p} \lambda_{i m}^{2}\right) / n$, onde $P V E_{m}$ representa o percentual de variancia explicada pelo m-ésimo fator, $m=1,2,3,4$ e 5 , e $\lambda_{\mathrm{m} m}$ denota a carga fatorial para o i-ésimo item, $i=1,2, \ldots, n(n=62)$, no fator $m$. 
l'metrmetros dos itents setgundo o modelo MC3

\begin{tabular}{|c|c|c|c|c|c|c|c|c|c|c|}
\hline \multirow{3}{*}{1} & & & 15 & at & & & & & & \\
\hline & 11 & 0.139 & 0.437 & $1.13 \%$ & 0.701 & 0.235 & $-0,56$ & 0.281 & 1.491 & -0.2 \\
\hline & 12 & 807. & $2 \pi$ & 228 & 6.276: & 0.1576 & 50.388 & 41 & 153 & 53 \\
\hline 3 & 13 & 0.142 & -3.745 & 2.448 & 0.216 & 0.519 & -0.194 & 0.803 & 2644 & 41 \\
\hline & 14 & 262 & 51.895 & 1.73 & 20. & 02 & teas & 0.630 & 10892 & 101 \\
\hline 5 & 15 & 3 & -1.760 & 2.446 & 0.369 & -0.161 & -0.388 & 0.8 & 26 & \\
\hline 6 & (6. & 8352 & 0.062 & 1.464 & 0.197 & 0.087 & -0. & 0.270 & [0,50 & 0.067 \\
\hline 7 & 17 & 0.130 & -0.131 & 0.672 & 0.249 & 0.115 & 0.082 & 0.071 & 0.643 & 0.203 \\
\hline 8 & 18. & 0.222 & -1.007 & 1.152 & C.35s & 0.095 & E.4.419: & 0140 & 1.356 & 0.749 \\
\hline 9 & 19 & 0.251 & -1.055 & 1.763 & 1.227 & -0.342 & 0. & & 2.583 & \\
\hline 嗗 & 110. & 0.389 & 96.647 & 1048: & 106669 & 0.352 & (2)333 & 0.096 & 1.339 & 0.483 \\
\hline 11 & 111 & 0.126 & -3.308 & 2.072 & 0.309 & -0.287 & $-0,203$ & 1.434 & 2.583 & 1.291 \\
\hline 2. & 112 & 0237 & 0.668 & 2.002 & 1354 & -0.160 & 0.236 & 0.897 & 2.241 & 0.387 \\
\hline 13 & 113 & 0.140 & $-1.161=$ & 1.706 & 0.922 & 0.469 & -0.335 & 0.692 & 2170 & 0.000 \\
\hline 繁 & 114 & 0,396 & 671 & 3497 & 0.6012 & 0.368 & -0.359 & 1.384 & 843 & 476 \\
\hline 15 & 115 & 0.109 & -1.159 & 0.671 & 0.002 & 0.220 & 0.059 & 0.430 & 0.750 & 1.545 \\
\hline 6. & (116. & 0.150 & 0.648 & 0.04 & 0.425 & 0.024 & 0.105 & 0.470 & .908 & 0.714 \\
\hline 17 & 117: & 0.041 & 0.583 & 0.896 & 0.386 & 0.219 & -0.083 & 0.150 & 1.014 & -0.575 \\
\hline 8 & 198 & & 023 & 83 & 0.64 & 0000 & 02 & 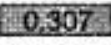 & Atows & 0.019 \\
\hline 19 & 119 & 0.025 & 0.053 & 1.005 & 0.387 & -0.508 & .0 .274 & 0.334 & 1.266 & -0.042 \\
\hline 20. & 120 & 0225 & 0.797. & 1.285 & 19 & -0 & B.192: & 849 & 1801 & 0.496 \\
\hline 21 & 121 : & 0.234 & 6.958 & 2.214 & 0.110 & -0.420 & -0.221 & 1.655 & 2.807 & 479 \\
\hline 52 & 122. & & 36 & bi. & ats & $4:$ & 154,0001 & $0.2 \pi$ & [2] & 0.025 \\
\hline 23 & 123 & 0.163 & 1,568 & 1.499 & 0.907 & 0. & -0.512 & 0. & 1.858 & 0.845 \\
\hline 24: & 124. & 247 & 356 & 198 & 143 & 0.3 & 29: & 0.873 & 420 & 251 \\
\hline 25 & 126 & $0: 120$ & 5.2224 & 2.263 & 0.618 & -0.553 & 10: & .074 & 2.666 & 30 \\
\hline$=$ & 126. & pan & U:81/7 & $3 n$ & $0.6 s$ & 00089 & & & odll. & sole \\
\hline 27 & 127 & & -0 & 1.693 & 0.1 & & & $0 . x$ & 1.8 & \\
\hline 28 & 128 & 0.062 & 0.3888 & 17550 & 198 & 0,109 & 10.342 & 1.226 & $12: 236$ & क्र151 \\
\hline 29 & 129 & 0.287 & 3.211 & 1.622 & 0.9 & 0.040 & -0.579 & 1.4 & 2415 & 1.329 \\
\hline 30 & 130 & 7 & 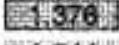 & 092 & 0. & 0 & Loliz8 & 000 & 51. & 11019 \\
\hline 31 & 131 & 0.136 & 1. & 0.964 & 0.7 & & & 7 & 1.232 & -1.253 \\
\hline 82. & 32 & 1572 & E. & 0.761 & 69.157 & 0.002 & 0.043 & 676 & 1.031 & 0348 \\
\hline 33 & 133 & 0.231 & -3.106 & 0.984 & 0.380 & 0.098 & -0.078 & 0.822 & 1.343 & 3 \\
\hline 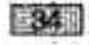 & 34. & 0.162 & [91176. & 1.03 & 28. & 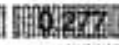 & $10 \sqrt{2}$ & 0.817 & twon & \\
\hline 35 & 135 & 0.235 & -2.420 & 1.68 & 0.662 & -0.416 & & 0.899 & 2.006 & \\
\hline 86 & 136 & 3 & Fo. & 1.602. & 9.844 & 0.300 & 0.082 & E12825 & 28577 & 0.055 \\
\hline 37 & 137 & 0.161 & -0.412 & 1.336 & 0.494 & 0.614 & 0.229 & 1.097 & 1.914 & 0.215 \\
\hline 38 & 38 & ai & 10.8 & 0.49 & 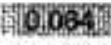 & 10.016 & DOF69 & (0.) & C6.653 & 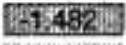 \\
\hline 39 & 139 & 0. & -0.789 & 0.465 & 0. & & 0.101 & & 0.586 & 1.3 \\
\hline & & & & & & & & & & \\
\hline
\end{tabular}




\begin{tabular}{|c|c|c|c|c|c|c|c|c|c|c|}
\hline & & E & & a & & 23 & $\mathbf{m}$ & & & \\
\hline 41 & 41 & 0.046 & -0.142 & $0.7 B 4$ & 0.442 & 0.057 & $2 \pi$ & 0.482 & 1.000 & 0.142 \\
\hline (i: & 42. & Q. & $-0,2 \pi 4$ & 0.918 & 5 get & 0.149 & 02397 & 0.220 & 13 & 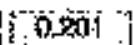 \\
\hline 43 & 143 & & $n 1$. & & 7 & 107 & & 288 & & \\
\hline 4 & {$\left[\mathrm{Al}^{-1}\right]$} & [E] & 024 & 9.885 & 0 & 0.70 & 6244 & 0.621 & 1.7 & D.21 \\
\hline 46 & 149 & 0.219 & 0.226 & C.897 & 199 & 0.146 & & 0.394 & 1. & \\
\hline 40$]$ & 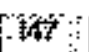 & orts & 0.449 & 1454 & 9.846 & 0.620 & $b . € 2 E^{\prime}$ & ?.670 & 160 & 02 \\
\hline 47 & 146 & 0,074 & 976 & $1.00 / 4$ & $.66 ?$ & 0.150 & $\infty$ & 0.211 & 1.2 & -0.1 \\
\hline $48:$ & 4 & $80.7 \%$ & 6.347 & 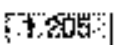 & $\Gamma 012$ & 04454 & 0.160 & $0.32+1$ & $469^{\circ}$ & rows \\
\hline 48 & 150 & 0.160 & -4.219 & 1.590 & 0.748 & 0.159 & 008 & 1,020 & 2045 & 6 \\
\hline 60 & 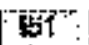 & 0.149 & 0.607 & 1.392 & $0.8059^{\circ}$ & 831 & 0.38 & $0.4 \$$ & 1.7 & 02 \\
\hline 51 & 152 & 0.006 & 1.210 & 1.D6s & 0.804 & -0.568 & 0.216 & .414 & .429 & CDEAG \\
\hline 5 & Ft: & 0.047 & 0,003 & 2965 & 0,743 & a.jos & $0.12 \mathrm{a}$ & ob & $.2 \pi$ & 0.0 \\
\hline$E 8$ & 154 & 0.134 & 0,034 & $1: 173$ & 0.574 & $0.2 \%$ & 0.396 & 0.644 & 503 & 0.349 \\
\hline 54 & sto & 0,200 & 0,1560 & $1.5 \mathrm{~N}$ & 0.485 & 0.718 & 46 & 0.235 & 1.563 & \\
\hline 5 & {$[5 \theta$} & 0.0 & 1.218 & 1.528 & 135 & 0,298 & 222 & 618 & 21. & 3 \\
\hline 56 & $5 \%: 1$ & 西 & 0.962. & $0 . \overline{368}$ & 0.249 & 0225 & 0.329 & 0.494 & $1 ; 1015$ & \\
\hline 字 & [ES & & -1.711 & 35 & 0.797 & 038 & 0.028 & 455 & 45 & \\
\hline 这 & \$ & Q6A & 604 & 0.86 & 0,643 & 9101 & $\theta 103$ & 0.44 & Oojot. & 2.47. \\
\hline 59 & {$[60$} & d. & & 32 & & & & (⿻) & 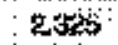 & \\
\hline bi & $\mathrm{BA}$ & $\bar{a}-\bar{r}$ & $\mid-1649$ & 4402 & 0.458 & d. & 0.31 & 0.584 & 1.679 & 0.82 \\
\hline 91 & 1042 & & -0.0 & & 895 & 3 & & 182 & & \\
\hline 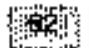 & 63 & 6165 & {$[-427$} & 103 & (1) द & ande & A.Tht & $0.78 \%$ & 1,804 & 0.106 \\
\hline
\end{tabular}

\section{Refexîncias}

ACKLRMAX, T. A. Lridimensional IRT calibrition of compensatory and noncompensatury itemts. Applifed Psycholugical Mcastrement, 13, 1989, 113-127.

Graphioal represontation of multidimmsionsal itom rosponse theory analysis. Applicd Psychologival Moasurement, 20, 1996, 311-329.

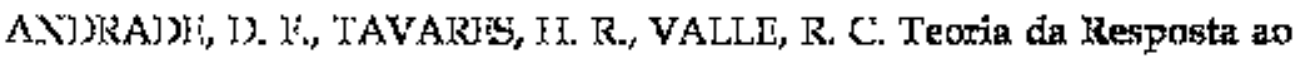

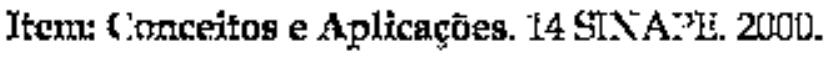

BAKL IR, Y. B. Ifem Response Theory - Parameter Estimation Techniques. Yew York: Marcel I Jekkex, Inc., 1992. 
BIRNBAUM, A. Efficient design and use of a mental ability for various decision-making problems, (Series Report No. 58-16. Project No. 7755-23). USAF School of Aviation Medicine, Texas: Randolph Air Force Base), 1957.

BOCK, R.D., AITKIN, M. Marginal maximum likelihood estimation of item parameters: application of an em algorithm. Psychometrika, 46, 1981, 443459.

DEMPSTER, A. P., LAIRD, N. M., RUBIN, D. B. Maximum likelihood from incomplete data via the EM algorithm. Journal of the Royal Statistical Society, Series B, 39,1977, 1-38.

DIVGI, D. R. Calculation of the tetrachoric correlation coefficient. Psychometrika, 44, 1979, 169-172.

FRASER, C., MCDONALD, R. P. NOHARM II: A FORTRAN program for fitting both unidimensional and multidimensional normal ogive models of latent trait theory [Computer software]. Armidale, Australia: University of News Wngland, Centre for Behavioral Studies, 1988.

HAMBLETON, R. K., SWAMINATHAN, H. Item Response Theory: Principles and Applications, Boston: Kluwer Academic Publishers, 1985.

HATTIE, J. A. Methodology Review: assessing undimensionality of tests and items: Applied psychological Measurement, 9, 1985, 139-164.

HSU, Y. Item parameter estimation of a two-dimensional generalized MIRT model (Doctoral dissertation, University of Illinois, 1995). Dissertation Abstracts International, 57, 1995, 1584.

Instituto Nacional de Estudos e Pesquisas Educacionais - INEP/MEC Exame Nacional do Ensino Médio - ENEM: Relatório Final. Brasília: O Instituto, 1999.

Instituto Nacional de Estudos e Pesquisas Educacionais - INEP/MEC Exame Nacional do Ensino Médio - ENEM: Documento Básico\}. Brasilia: O Instituto, 2000.

JOHNSON, R. A., Wichern, D. W. Applied Multivariate Statistical Analysis, 4nd Ed. New Jersey: Prentice Hall, 1998.

LAROS, J. A., PASQUALI, L., Rodrigues, M. M. M. Análise da Unidimensionalidade das Provas do SAEB. Universidade de Brasflia, 2000.

LAWLEY, D. N., Maxwell, A. E. Factor Analysis as a Statistical Method, 2nd Ed. London: Butterworth, 1971.

LINDEN, W. J. van der, HAMBLETON, R. K. Handbook of Modern Item Response Theory. New York: Springer-Verlag, 1997. 
LIM, C. An application of the joint maximum likelihood estimation procedure to a two-dimensional case of Sympson's noncompensatory IRT model (Doctotal dissertation, University of Iowa, 1993. Dissertation Abstracts Interntaional, 54, 1993, 2549.

LORD, F. M. Applications of Item Response Theory to Pratical Testing Problems. Hillsdale: Lawrence Erlbaum Associates, Inc., 1980.

MATOS, G. S. Teoria da Resposta ao Item: Uma Proposta de Modelo Multivariado. Dissertação de Mestrado apresentada à Universidade Federal de Pernambuco. Pernambuco, 2001.

MCDONALD, R. P., AHLAWAT, W. S. Difficulty factors in binary data. British Journal of Mathematical and Statistical Psychology, 27, 1974, 8299.

MISLEVY, R. J., Bock, R. D. BILOG 3: Item Analysis and Test Scoring with Binary Logistic Models. Chicago: Scientific Software, Inc., 1990.

PEARSON, K. On the correlation of characters not quantitatively measurable. Royal Society Philosophical Transactions, Series A, 195, 1900, 1-47.

RECKASE, M. D. The difficult of test items that measure more than one ability. Applied Psychological Measurement, 9, 1985, 401-412.

RECKASE, M. D. Controlling the psychometric snake: Or, how I learned to love multidimensionality. Invited address at the meeting of the American Psychological Association, New Orleans, 1989.

RECKASE, M. D., McKinkey, R. L. The discriminating power of items that measure more than one dimension. Applied Psychological Measurement, 15, 1991, 361-373.

SYMPSON, J. B. A model for testing multidimensional items. In D. J. Weiss (Ed.) Proceedings of the 1977 computerized adaptive testing conference (pp. 82-98). Minneapolis: University of Minnesota, Department of Psychology, Psychometric Methods program, 1978.

TAVARES, H. R. Teoria da Resposta ao Item para Dados Longitudinais. Tese de Doutorado apresentada à Universidade de São Paulo. São Paulo, 2001.

WILSON, D.T., Wood, R., Gibbons, R. TESTFACT: Test Scoring, Item Statistics and Item Factor Analysis. Chicago: Scientific Software, Inc, 1998. 